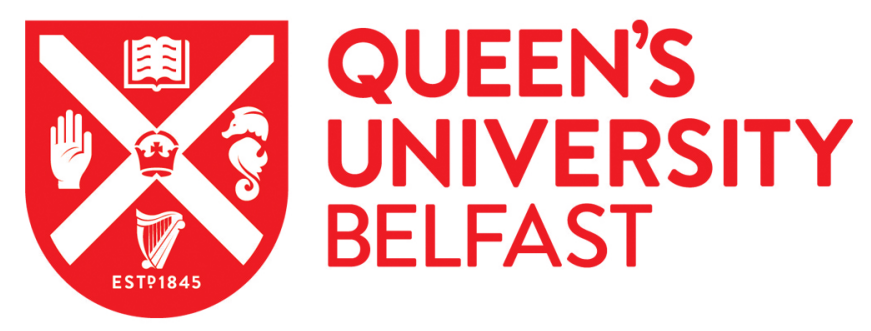

\title{
Assessing the current modelling approach for predicting the crashworthiness of Formula One composite structures
}

Dalli, D., Varandas, L., Catalanotti, G., Foster, S., \& Falzon, B. (2020). Assessing the current modelling approach for predicting the crashworthiness of Formula One composite structures. Composites Part B: Engineering. https://doi.org/10.1016/j.compositesb.2020.108242

\section{Published in:}

Composites Part B: Engineering

\section{Document Version:}

Peer reviewed version

Queen's University Belfast - Research Portal:

Link to publication record in Queen's University Belfast Research Portal

\section{Publisher rights}

Copyright 2020 Elsevier

This manuscript is distributed under a Creative Commons Attribution-NonCommercial-NoDerivs License

(https://creativecommons.org/licenses/by-nc-nd/4.0/), which permits distribution and reproduction for non-commercial purposes, provided the author and source are cited.

\section{General rights}

Copyright for the publications made accessible via the Queen's University Belfast Research Portal is retained by the author(s) and / or other copyright owners and it is a condition of accessing these publications that users recognise and abide by the legal requirements associated with these rights.

Take down policy

The Research Portal is Queen's institutional repository that provides access to Queen's research output. Every effort has been made to ensure that content in the Research Portal does not infringe any person's rights, or applicable UK laws. If you discover content in the Research Portal that you believe breaches copyright or violates any law, please contact openaccess@qub.ac.uk. 


\section{Journal Pre-proof}

Assessing the current modelling approach for predicting the crashworthiness of Formula One composite structures

D. Dalli, L.F. Varandas, G. Catalanotti, S. Foster, B.G. Falzon

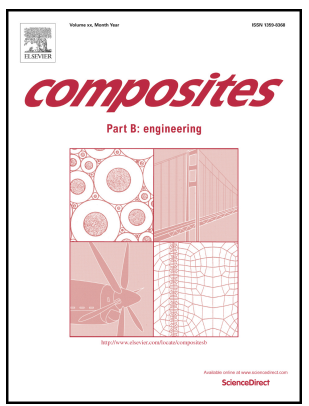

PII:

S1359-8368(20)33292-3

DOI: https://doi.org/10.1016/j.compositesb.2020.108242

Reference: JCOMB 108242

To appear in: Composites Part B

Received Date: 22 March 2020

Revised Date: 18 May 2020

Accepted Date: 8 June 2020

Please cite this article as: Dalli D, Varandas LF, Catalanotti G, Foster S, Falzon BG, Assessing the current modelling approach for predicting the crashworthiness of Formula One composite structures, Composites Part B, https://doi.org/10.1016/j.compositesb.2020.108242.

This is a PDF file of an article that has undergone enhancements after acceptance, such as the addition of a cover page and metadata, and formatting for readability, but it is not yet the definitive version of record. This version will undergo additional copyediting, typesetting and review before it is published in its final form, but we are providing this version to give early visibility of the article. Please note that, during the production process, errors may be discovered which could affect the content, and all legal disclaimers that apply to the journal pertain.

() 2020 Elsevier Ltd. All rights reserved. 
Denis Dalli: Conceptualisation, Methodology, Investigation, Validation, Writing - original draft, review \&editing.

Luis F. Varandas: Conceptualisation, Methodology, Investigation, Validation, Writing - original draft, review \&editing.

Giuseppe Catalanotti: Conceptualisation, Writing - review \&editing, Supervision.

Steve Foster: Conceptualisation, Resources, Writing - review \&editing.

Brian G. Falzon: Conceptualisation, Writing - review \& editing, Supervision, Funding acquisition. 


\title{
Assessing the current modelling approach for predicting the crashworthiness of Formula One composite structures
}

\author{
D. Dalli ${ }^{1}$, L. F. Varandas ${ }^{1}$, G. Catalanotti ${ }^{1}$, S. Foster ${ }^{2}$, B. G. Falzon ${ }^{1} *$ \\ ${ }^{1}$ Advanced Composites Research Group (ACRG), School of Mechanical and Aerospace Engineering, Queen's \\ University Belfast, Ashby Building, Stranmillis Road, Belfast BT9 5AH, UK. \\ ${ }^{2}$ McLaren Racing Limited, McLaren Technology Centre, Chertsey Road, Woking, Surrey, GU21 4YH, UK.
}

\begin{abstract}
Current methods for designing Formula One (F1) crash structures are mainly based on costly iterative experiments, aimed at minimising the component mass and maximising driver safety. This paper assesses the simplified block approach used in F1 to computationally predict crashworthiness. Quasi-static and dynamic crush experiments of flat and tubular coupons are presented, to generate data for the modelling of a F1 Side Impact Structure (SIS). The crushing efficiency of these coupons is found to be dependent on geometry, ply orientation, and crushing velocity. This modelling strategy yields results which compare favourably with those obtained from the quasi-static and dynamic experimental testing of a full-scale SIS, but also highlight areas which require further work to improve accuracy.
\end{abstract}

Keywords: (A) Carbon fibre, (B) Damage tolerance, (C) Numerical analysis, (D) Mechanical testing, F1 crash structures

\footnotetext{
* Corresponding author.

E-mail address: B.Falzon@qub.ac.uk (B.G.Falzon).
} 


\begin{tabular}{|c|c|}
\hline \multicolumn{2}{|c|}{ Abbreviations and nomenclature } \\
\hline $2 \mathrm{D}, 3 \mathrm{D}$ & 2-dimensional and 3-dimensional \\
\hline $5 \mathrm{HS}$ & 5-Harness-Satin \\
\hline$A$ & specimen cross-sectional area \\
\hline $\mathrm{BC}$ & Boundary condition \\
\hline CAD & Computer-Aided Design \\
\hline $\mathrm{CDM}$ & Continuum Damage Mechanics \\
\hline CFRP & Carbon Fibre Reinforced Polymer \\
\hline $\mathrm{CIC}$ & Cranfield Impact Centre \\
\hline $\mathrm{CNC}$ & Computer Numerical Control \\
\hline$D$ & internal tube diameter \\
\hline DYN & dynamic \\
\hline$F$ & load \\
\hline FE & finite element \\
\hline $\mathrm{F} 1$ & Formula One \\
\hline$m$ & crushed mass of the Formula One Side Impact Structure \\
\hline QS & quasi-static \\
\hline$s$ & crushing length \\
\hline$S E A$ & specific energy absorption \\
\hline SIS & Formula One Side Impact Structure \\
\hline S3R, S4R & triangular and quadrangular reduced-integration shell elements \\
\hline$t$ & laminate thickness \\
\hline TTT & triangular through-thickness \\
\hline UD & unidirectional \\
\hline$V_{z}$ & velocity of the crushing plate \\
\hline VUMAT & user defined material for Abaqus ${ }^{\circledR} /$ Explicit \\
\hline VUSDFLD & user defined field for Abaqus ${ }^{\circledR} /$ Explicit \\
\hline$\sigma$ & stress \\
\hline$\sigma_{C r}$ & crush stress parameter \\
\hline
\end{tabular}




\section{Introduction}

Over the years, motorsport, including Formula One (F1), has experienced tragic incidents with the loss of life of both drivers and spectators. While the latter have been easier to protect, through the erection of fences and the strategic location of spectator stands away from the track, the drivers are still subjected to potentially fatal crashes. One of the major safety improvements in F1 has been the introduction of carbon fibre composite crash structures [1]. These structures, found at the front, rear, and sides of each car, are designed to absorb energy during crash events, and thus protect the driver. F1 structures involve complex 3D geometries due to aerodynamic requirements, making their energy absorbing capacity more challenging to design for.

F1 composite structures are costly to produce, and they need to be experimentally certified before deployment. The certification of crash structures is more complex than that of other components since the use of a safety factor cannot be applied in crashworthiness. An overly conservative crash structure design, apart from being unnecessarily heavy, could prove fatal, by subjecting the driver to excessively large decelerations. More often, engineers risk having less conservative crash structures, as they seek ways to reduce their mass. This could still prove fatal, if the structure does not absorb enough energy during crushing, allowing the driver's safety cell to bear the brunt of the impact. Thus, such structures are meant to operate within tight performance limits of energy absorption and need to be properly designed. This problem is further exacerbated for the front and rear F1 crash structures, which also need to perform as load bearing components [2]. The first step towards improving the design methods of crash structures is to understand the manner in which current structures crush, mainly by identifying the governing failure mechanisms.

Several studies have attempted to assess the crashworthiness of carbon fibre reinforced composites, by testing coupon specimens and identifying their failure mechanisms. Different coupon designs and loading fixtures have been tested, including both open section (e.g. flat [3-7], corrugated/sinusoidal [8,9], C-channels [10,11], semi-circular [8,12]) and closed section (e.g. round tube [13-16], square tube $[11,17,18]$, double hat [19]) geometries, for a variety of unidirectional (UD), 2D, and 3D woven and braided architectures. The effects of different triggers $[5,7,20,21]$ and plug initiators $[22,23]$ on the development of different failure mechanisms have also been extensively investigated. Conflicting results have been reported on the effects of dynamic crushing on the Specific Energy Absorption (SEA) of materials. The measured SEA of various coupons has been reported to increase [14,18], decrease [4,12,24,25], or even remain constant $[14,15]$ under dynamic loading, when compared to quasi-static testing. However, SEA is known to be a structural property, and not just dependent on the material [5]. It is a function of the material (fibre, resin, and architecture), layup, coupon geometry, loading fixture, and crushing velocity. Furthermore, it is not always a geometrically scalable property [17].

Savage et al. [2] presented the results of an F1 rear impact structure subjected to crush conditions. At that time (2003), composite crash structures were already being designed, certified, and put to use in F1 cars. However, their design method for crashworthiness was very empirical, since the simulation tools available to 
F1 teams were not yet developed for modelling composite crushing [2]. Furthermore, they used quasi-static crush testing in their iterative design process, as a means of evaluating the crash structure performance, before finally performing a more costly dynamic test to acquire certification. There was no mention whether the quasi-static and dynamic tests performed differently. They also performed tubular coupon crush tests to assess the specific energy absorption of the materials available. Since then, simulation tools have been improved, with macro-scale level material damage models being made commercially available, and these are now being adopted by industry for crashworthiness modelling [26-28]. However, these models still require semiempirical material data to model crushing. This data is usually obtained from coupon testing, and is dependent on laminate layup, coupon curvature, and crushing velocity [26]. Thus, a large number of coupon tests need to be performed to model a complex structure, and there is no certainty that the crushing behaviour of a small coupon reflects structural behaviour. Due to this uncertainty, there is no consensus on the coupon geometries which should be tested in order to provide material crush parameters into the crush simulations of complex structures. Bisagni et al. [29] also presented experimental dynamic crush results of an F1 crash structure. However, no details were provided on the material properties, possibly due to confidentiality reasons, which could have allowed the crush simulation results to be benchmarked.

The mandatory crash structure currently used on the sides of each F1 car, known as a Side Impact Structure (SIS), is based on a homologated design. This ensures that all teams need to use the exact same SIS design and material, unlike the front and rear crash structures which are developed by the individual teams. The SIS is a small monolithic component and is easier and cheaper to manufacture when compared to the other F1 crash structures, which are usually larger sandwich laminates with honeycomb cores. This also makes the SIS easier to simulate, and an ideal representative specimen to benchmark simulation tools.

This paper presents the experimental uniaxial crushing of a standard upper SIS, tested at both quasi-static and dynamic rates, in order to assess whether such CFRP structures exhibit a rate-dependent specific energy absorption. Flat and tubular coupons were experimentally tested, to obtain geometry-dependent crush stress parameters [26,27], since the SIS geometry includes a range of curvatures, which could promote different crushing modes [26]. The crush stress parameters were then used for macro-scale (laminate-level) crush simulations of the SIS, generated using the software package Abaqus ${ }^{\circledR}$ [30]. These quasi-static and dynamic Finite Element (FE) crush simulations made use of an Abaqus ${ }^{\circledR}$ in-built orthotropic composite damage model [31], combined with the CZone add-on to capture the crushing behaviour at the crash-front of the SIS. In summary, this paper presents a comprehensive set of experimental data which can be used to develop a benchmark for numerical predictive tools for structural composite crushing. This paper also aims to start off this benchmark by assessing the current numerical approach being taken by F1 teams, and highlighting its current shortcomings. 


\section{Experimental testing and results Journal Pre-proof}

\subsection{Geometries, material, and manufacturing}

The homologated SISs of current F1 cars are manufactured from a balanced 5-Harness-Satin (5HS) woven CFRP which was characterised in previous work [32,33]. There are actually two SIS design variants on each side of an F1 car, referred to as upper and lower [34], each composed of a different number of plies. These two SIS variants are located in the base and at the top of each side-pod, respectively (refer to Figure 1b). In this study the upper SIS design was investigated, since it required less material to be made. This structure is composed of 14 plies at its base. The layup tapers through a 6 ply drop-off, at a rate of 1 ply every $3 \mathrm{~mm}$, leaving 8 plies within its entire crushing region of $277 \mathrm{~mm}$ (see Figure $2 \mathrm{~b}$ ). The layup for the SIS was $\left[+45^{\circ} / \mathbf{0} \% \mathbf{4 5} \%-\mathbf{4 5} \%-\mathbf{4 5} \% \mathbf{+ 4 5} \% \mathbf{0}^{\circ} / 0^{\circ} /-45^{\circ} / 90^{\circ} / 90 \%-45^{\circ} / 0^{\circ} /+45^{\circ}\right]$, where the drop-off plies $2-7$ are in bold. Please note that each angle refers to the fabric warp direction. The layup in the crushing region is $\left[+45^{\circ} / 0^{\circ}\right.$ $\left.45^{\circ} / 90^{\circ}\right]_{\mathrm{S}}$ with a nominal thickness of $2.4 \mathrm{~mm}$.

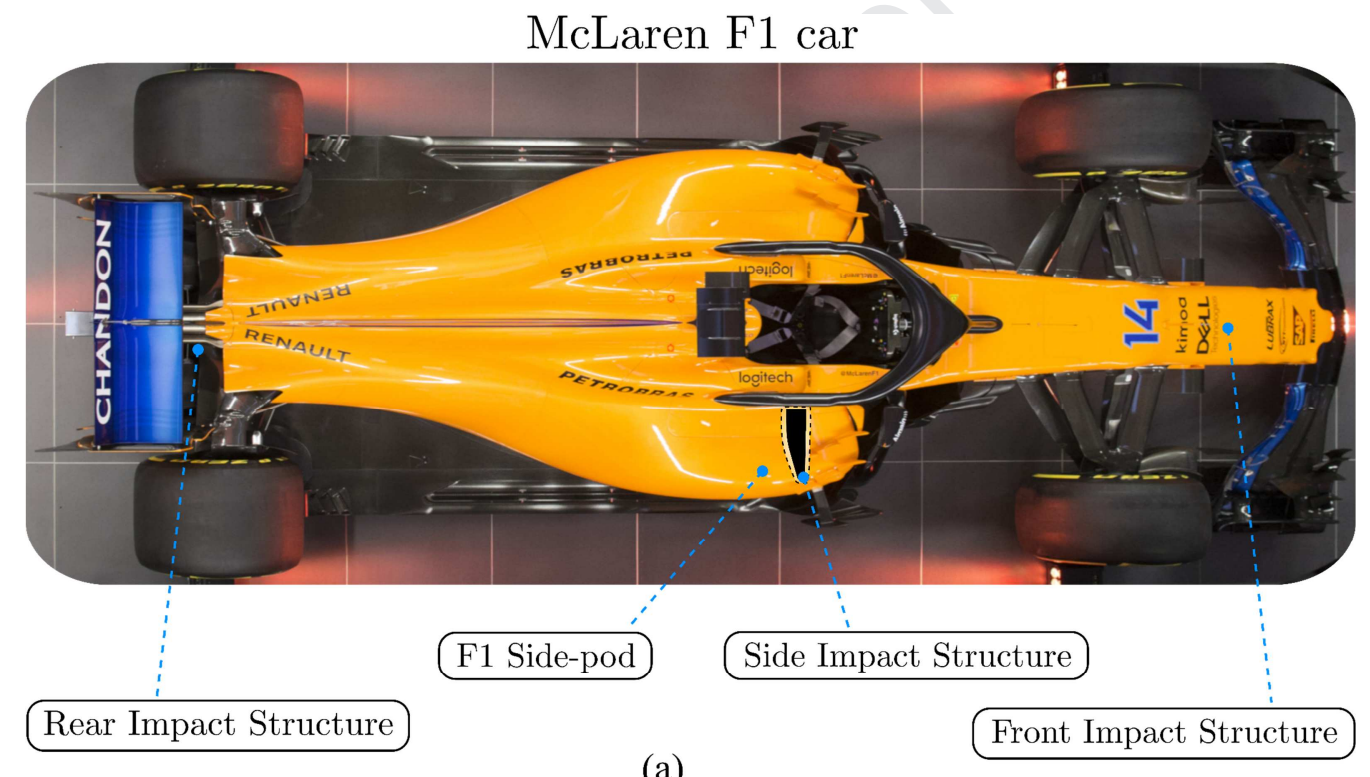

(a)

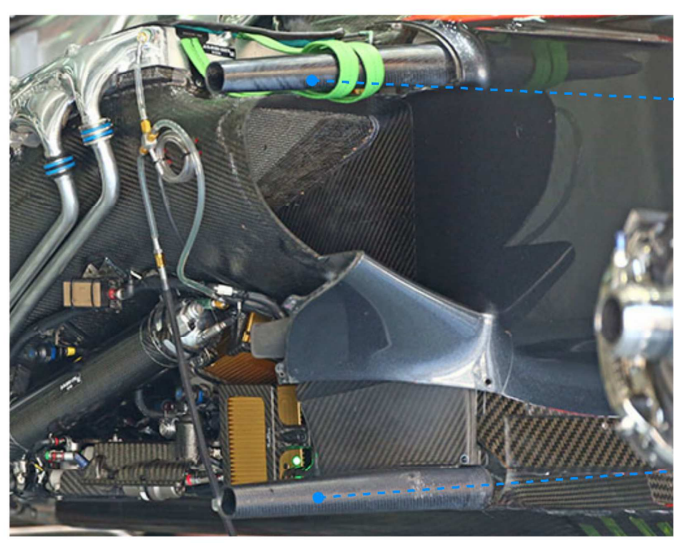

Upper Side Impact Structure

(b)

Figure 1 - (a) Position of crash structures within an F1 car; (b) upper and lower Side Impact Structures in an F1 side-pod (with the body-work removed) (adapted with permission from [35]). 
Figure 2a presents a schematic of the inboard and outboard layups of the SIS, including the ply numbers. The ply seams were located at a different position for each ply, in order to minimise the seam effect. This figure also highlights the presence of an internal rib, constructed from plies 13 and 14. The layup of the SIS starts with two internal male moulds, around which plies 14, and then 13, are draped. These two moulds are then brought together, forming a 4-ply internal rib. The remaining 12 plies are then draped around the joined moulds, on top of plies 13 and 14 . Figure $2 \mathrm{~b}$ presents an axial cross-section of the SIS, highlighting the six ply drop-off near the base of the structure.
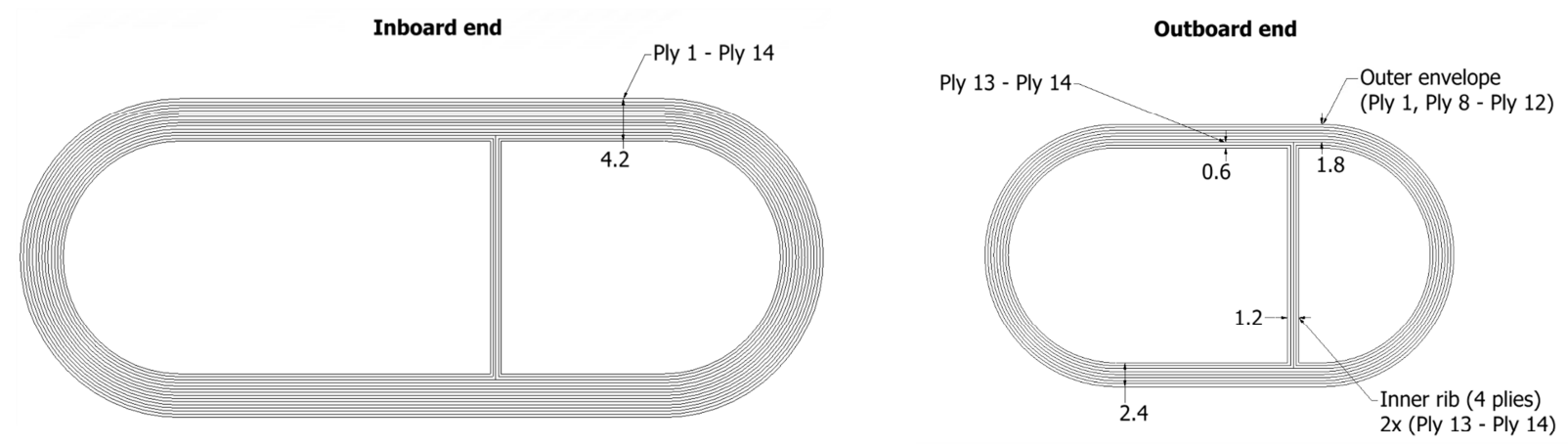

(a)

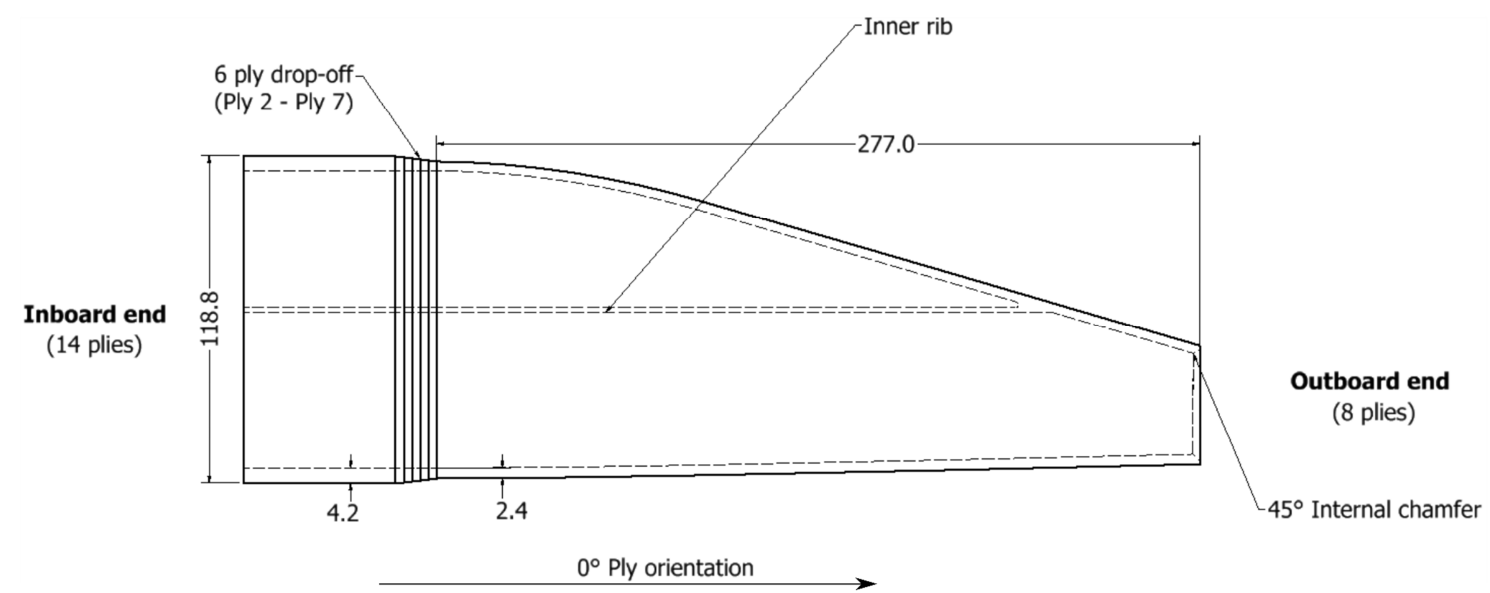

(b)

Figure 2 - (a) Representative layup schematics of the inboard and outboard ends of the SIS; (b) cross-sectional view of the SIS, including the 6 ply drop-offs (all linear dimensions are given in $\mathrm{mm}$ ).

Due to the complex geometry of the SIS, each prepreg ply was cut using a CNC cutter, as normally done for such components. The structures were cured in an autoclave, following the recommended curing cycle. A $45^{\circ}$ chamfer trigger was machined at the top end of each SIS, in order to promote progressive crushing. After trimming, each cured SIS had a nominal mass of $0.34 \mathrm{~kg}$. Figure 3a presents a trimmed SIS, shown from the side and bottom perspectives, for better visualisation. Each SIS was then mounted in a plastic base (Figure 3b), machined from solid resin, in order to allow the structures to be clamped in both quasi-static and dynamic experimental setups. The structures were fixed in these mounting bases using an epoxy adhesive. The top of the mounting base reached up to the start of the ply drop-off region. 

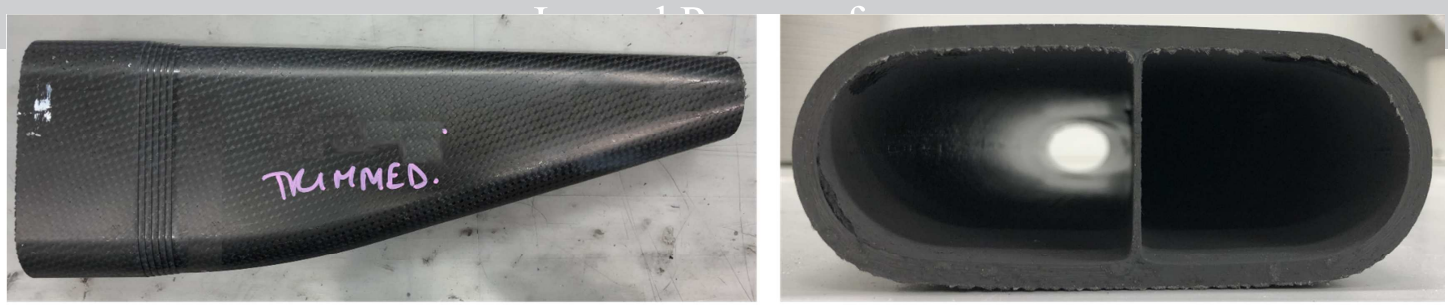

(a)

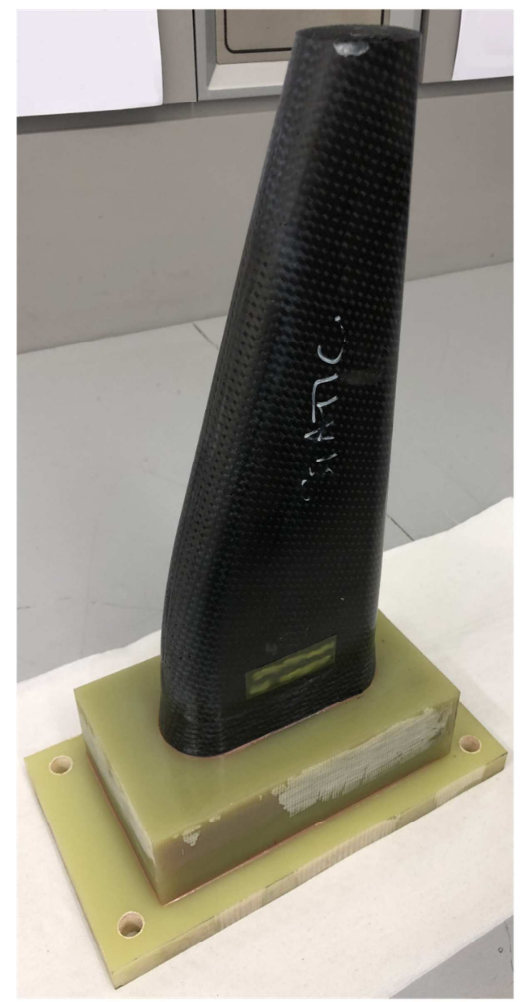

(b)

Figure 3 - Trimmed Side Impact Structure: (a) side and bottom views; (b) structure mounted in a resin base.

Flat and tubular coupons were also manufactured, in order to assess the crushing performance of the material at a coupon level, and to observe any possible geometrical effects on the crushing modes and energy absorption. All coupons were 8 plies thick, to match the thickness of the crushing region of the SIS (nominal thickness, $t=2.4 \mathrm{~mm})$. The tested coupon layups were $\left[0^{\circ} / 90^{\circ}\right]_{2 \mathrm{~S}},\left[+45^{\circ} /-45^{\circ}\right]_{2 \mathrm{~S}}$, and $\left[+45^{\circ} / 0^{\circ} /-45^{\circ} / 90^{\circ}\right]_{\mathrm{S}}$, the latter present in the crushing region of the SIS. These layups were tested in order to assess the influence of the ply orientation on the crushing performance of the material.

The flat coupons were cut from rectangular laminates, while the tubular coupons were cut from long tubes which were cured around a steel mandrel. Both coupon geometries necessitated the use of a trigger in order to initiate progressive crushing. The flat coupons were designed based on the crush coupon geometry proposed by Bru et al. [7], with a $30^{\circ}$ TTT (triangular through-thickness) trigger, albeit, in that work, UD composite specimens were tested. Since the repetitive unit cell of the woven material ( $8 \mathrm{~mm}$ square) is significantly larger than that of a UD, the flat specimens tested here were larger than the ones tested by Bru et al. [7], in order to capture a better representation of the progressive crushing of the woven laminates. The detailed 
geometry of the flat coupons is presented in Figure $4 \mathrm{a}$, including a $63.5 \mathrm{~mm}$ gripping length for the specimen to be held in the fixture. The internal diameter of the tubes, $D$, was chosen to be $32 \mathrm{~mm}$, as a close approximation to the curvature at the top of the SIS. These tubes, $60 \mathrm{~mm}$ in length, had a $45^{\circ}$ bevel/chamfer trigger, machined at the top edge, to promote crushing. This trigger was chosen over tulip shape triggers found in literature [15], since it was easier to machine. The closed section tube, presented in Figure 4b, was chosen since it is a free-standing geometry that does not require support during testing, and because the closed section avoids any free edge effects.

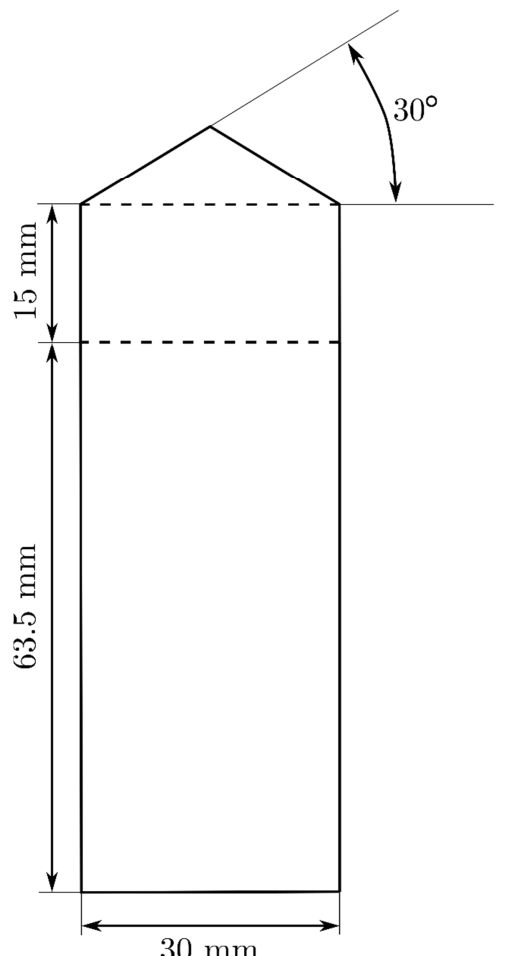

(a)

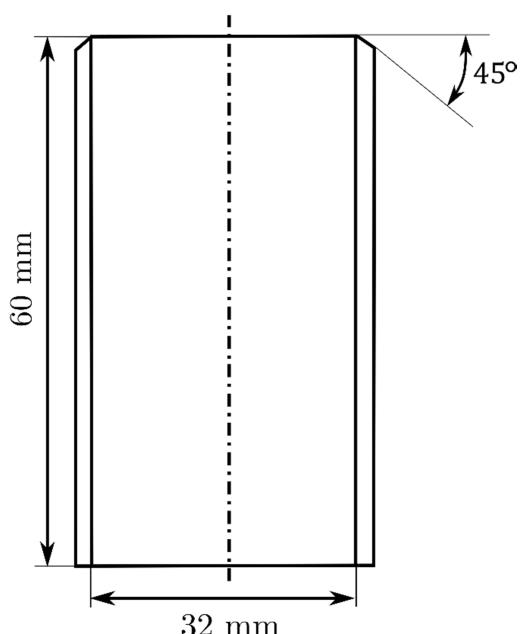

(b)

Figure 4 - (a) Flat coupon geometry schematic; and (b) tubular coupon cross-sectional geometry schematic.

\subsection{Experimental test setups}

\subsubsection{Quasi-static test setups}

\section{Coupons}

The quasi-static flat and tubular coupons were tested using an electromechanical test machine equipped with a $100 \mathrm{kN}$ load cell and a fixed head compression platen, under displacement-controlled loading at a rate of $2.5 \mathrm{~mm} / \mathrm{min}$. The flat coupons were supported during the test by means of a fixture, as shown in Figure $5 \mathrm{a}$. The clamping bolts of this fixture were finger-tightened, followed by a quarter turn using a hex key. This ensured the fixture would not open during testing, while making sure to avoid damaging the clamped surfaces of the coupons. The unsupported length of the flat coupons was $23.67 \mathrm{~mm}(8.67 \mathrm{~mm}$ of trigger length and 15 $\mathrm{mm}$ for constant cross-section crushing). The tubular coupons were self-supported and did not require a supporting fixture. They were crushed using the setup shown in Figure 5b. For the flat coupons, the tests were 
stopped after $20 \mathrm{~mm}$ of crushing, to avoid contact between the fixture and the loading platen, while the tubular tests were stopped after $30 \mathrm{~mm}$ of crush. Four flat and four tubular coupons were tested for each of the three layups.

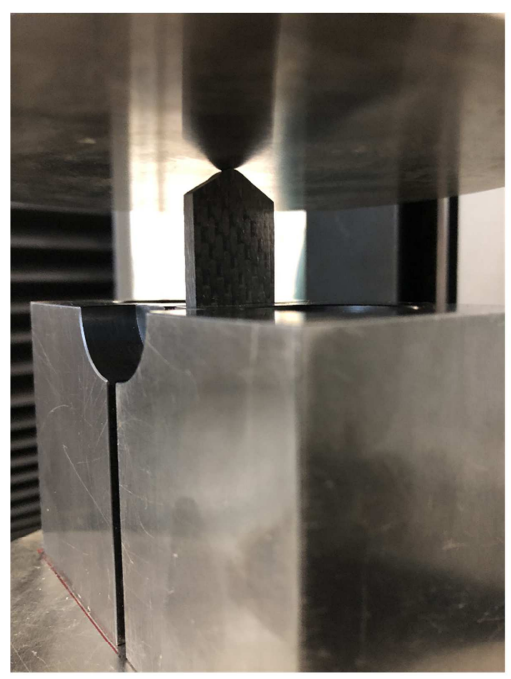

(a)

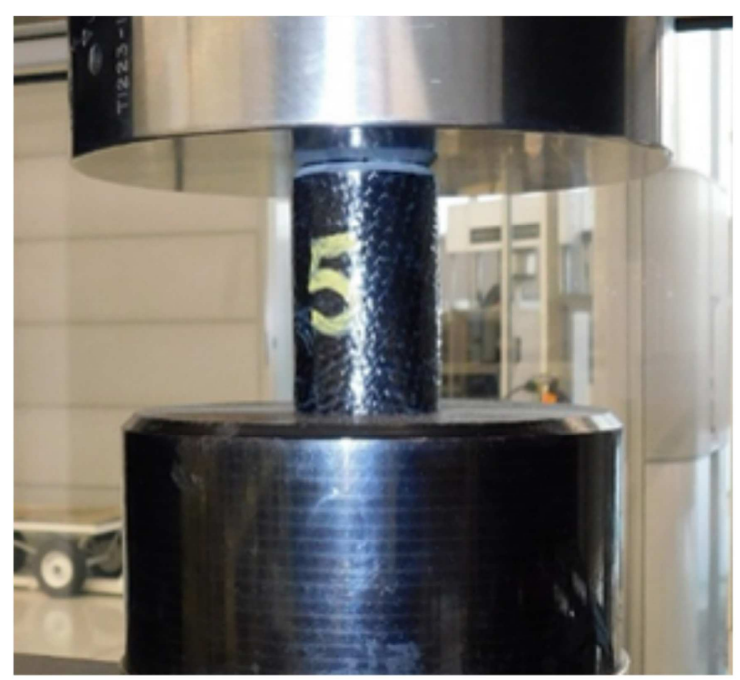

(b)

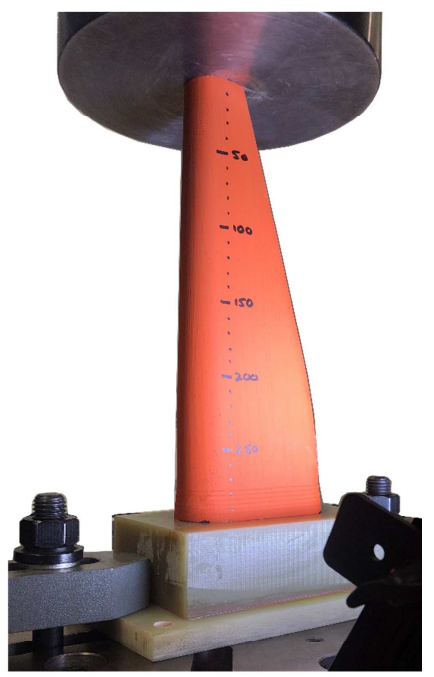

(c)

Figure 5 - Quasi-static test setups for the: (a) flat coupons; (b) tubular coupons; and (c) the Side Impact Structure.

\section{Side Impact Structures}

The quasi-static crushing of the SISs was performed in a similar electromechanical test machine, equipped with a $250 \mathrm{kN}$ load cell, with a $25 \mathrm{~mm} / \mathrm{min}$ displacement-controlled loading rate. This speed was chosen in order to not make the test excessively time consuming, while staying within the quasi-static regime. The tests were stopped after $250 \mathrm{~mm}$ of crushing. The quasi-static test setup of the SIS is shown in Figure 5c. Three SISs were tested under quasi-static crushing. The outer surface of the SISs was painted orange in order to be able to observe the crush progression more clearly.

\subsubsection{Dynamic test setups}

Coupons

A drop weight tower was used to dynamically crush the flat and tubular coupons. This testing was performed at the Cranfield Impact Centre (CIC). The flat coupons were supported using the same fixture as done for the quasi-static tests. The tubular coupons were again left unsupported. For both the flat and tubular coupon tests, a load cell was placed beneath the coupons, in order to measure the load, at a sampling rate of 20 $\mathrm{kHz}$. A $26 \mathrm{~kg}$ drop weight was used to crush the tubular coupons, while a $6.5 \mathrm{~kg}$ mass was used for the flat ones, due to the lower volume of material to be crushed in the latter. The target velocity at impact was set to 7 $\mathrm{m} / \mathrm{s}$ for both coupon types (the maximum achievable using this drop tower). Using this impact velocity and the respective drop weights, the flat coupons were completely crushed, while an $18 \mathrm{~mm}$ crushing length was obtained for the tubular coupons. Four flat and four tubular coupons were tested for each of the three layups. 


\section{Side Impact Structures}

The dynamic crushing of the SISs was also performed at Cranfield Impact Centre. Due to the significant amount of energy required to crush a SIS, the test could not be done using the drop tower used for the coupon tests. Instead, a sled impactor was used, with a mass of $780 \mathrm{~kg}$ (see Figure 6b), with a target impact velocity of $10 \mathrm{~m} / \mathrm{s}$ (equal to the test velocity required for F1 certification). Due to the cost of each crush experiment, two SISs were crushed in the same test run. The experimental setup of the two SIS is shown in Figure 6a, including the plastic mounting and metal support structure. Separate load cells were used to measure the crushing load for each SIS (see Figure 6c), with a sampling frequency of $20 \mathrm{kHz}$. High speed cameras were placed at the top and side of the SISs, to track their dynamic crushing.

The actual F1 dynamic experimental certification test for these SISs is performed at an oblique crushing angle, rather than a uniaxial one. This ensures that these crash structures are effective in an off-axis loading crush scenario. In order to simplify the quasi-static loading test setup, and to be able to compare its result to the dynamic test, the SISs were crushed axially for both loading regimes. 


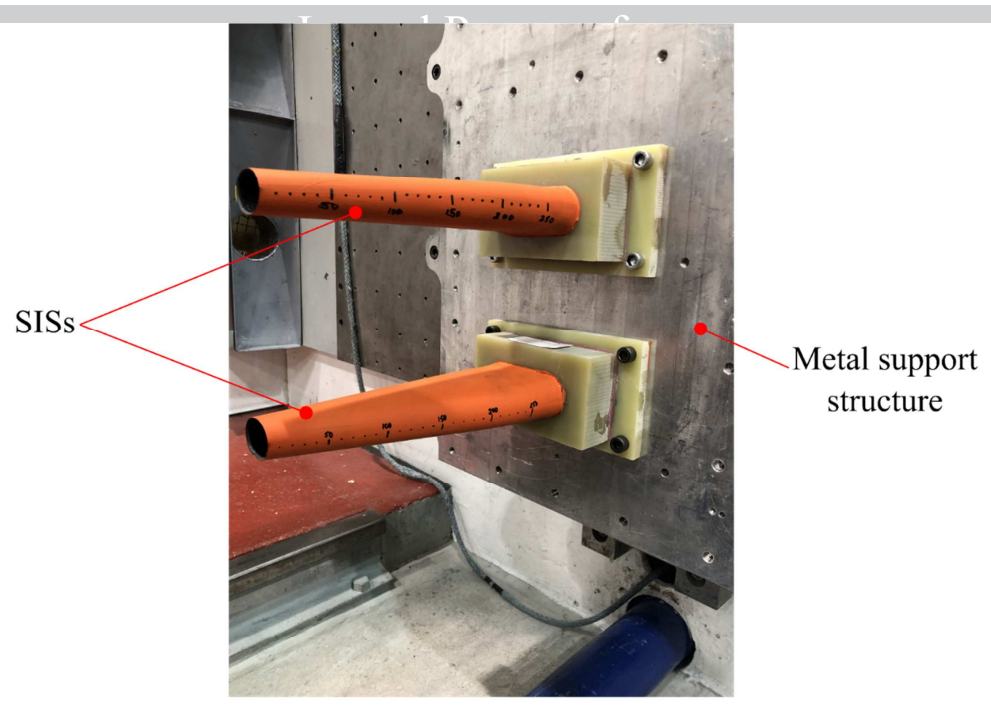

(a)

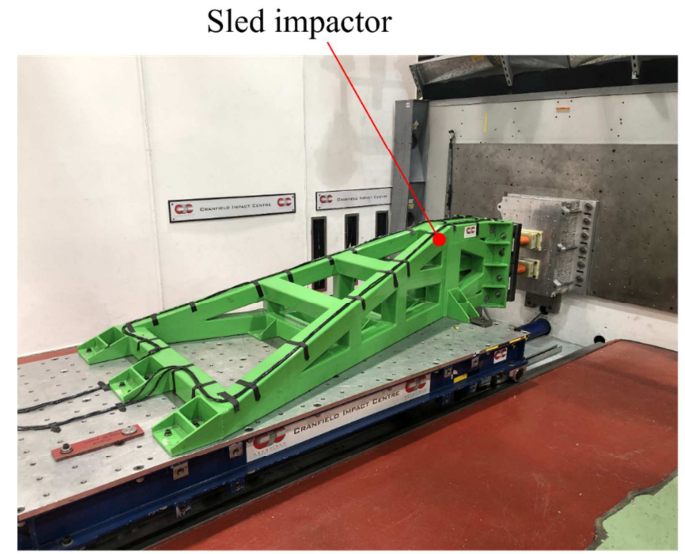

(b)

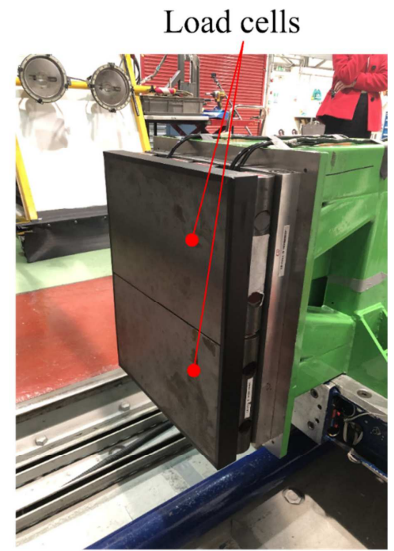

(c)

Figure 6 - Dynamic setup for Side Impact Structure (SIS) crushing: (a) two SISs mounted on a metal support structure; (b) $780 \mathrm{~kg}$ sled impactor; (c) two separate load cells to measure the individual crushing loads of both SIS.

\subsection{Experimental results}

\subsubsection{Coupons}

Quasi-static flat coupons

The quasi-static $\left[0^{\circ} / 90^{\circ}\right]_{2 S}$ flat coupons crushed in a stable progressive manner. Splaying was found to be the predominant damage mode, while some ply fragmentation was also observed for the central plies of the coupons. The crushing debris of the inner plies forced the outer plies to be bent outwards. Delamination fronts were created between the two outermost plies on each side of the coupons. As the amount of debris in the central region increased, and the outermost plies offered less support, more of the inner plies started to bend outwards in a similar manner to the outermost plies (as seen in [36]). After a significant progression of the crash-front, all of the plies ended up being bent outwards, with a central debris wedge being progressively forced to delaminate the plies beneath it. This debris wedge can be observed in Figure 7, together with the central delamination front that forms beneath it. The crushing mode of these coupons was observed to change progressively from ply fragmentation to splaying. The early ply fragmentation, which mainly involves intralaminar damage, is a more efficient energy absorption mechanism than interlaminar splaying [36]. This 
was corroborated by a progressive decrease in crushing load as splaying became more predominant. The various stages of crushing for a typical $\left[0^{\circ} / 90^{\circ}\right]_{2 S}$ coupon are shown in Figure 8, presented from two viewing angles, including: (a) the start of the test; (b) outer ply bending and initial delaminations; (c) initial bending of the inner plies, and; (d) splaying of all plies with a central debris wedge.

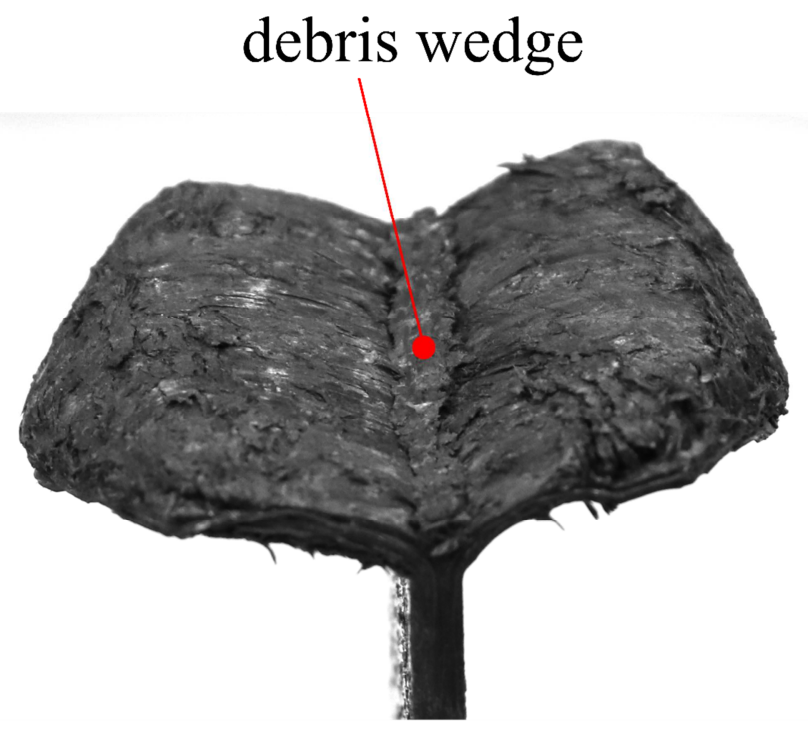

(a)

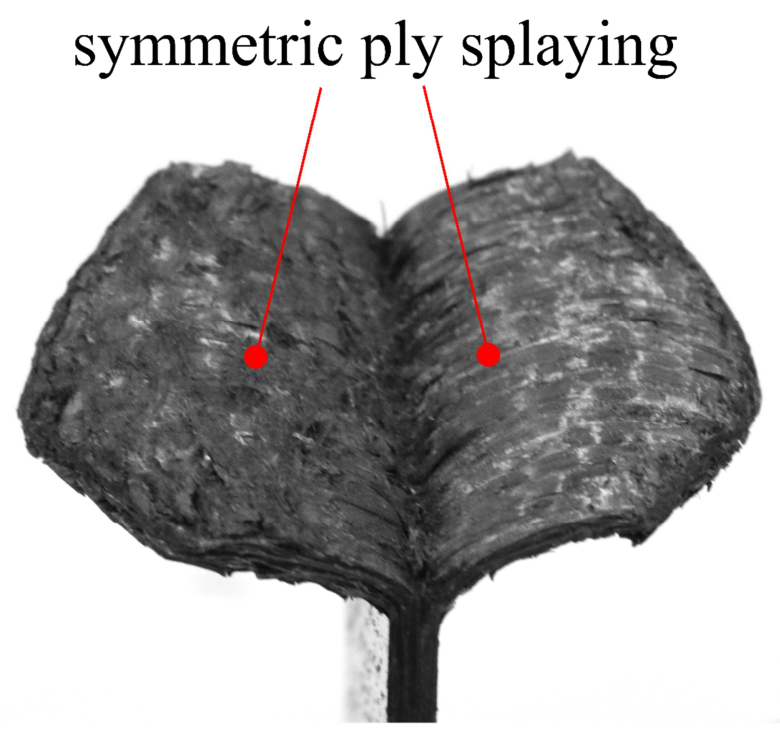

(b)

Figure 7 - Crushed $\left[0^{\circ} / 90^{\circ}\right]_{2 S}$ flat coupon: (a) with central debris wedge; and (b) with debris wedge removed.

Coupons made from the other two layups buckled during the crushing of the triangular trigger, as can be observed in Figure 9. The flat coupons for these layups were then shortened by $15 \mathrm{~mm}$, leaving only the triangular trigger exposed above the top of the fixture. The trigger of these specimens was then pre-crushed, using the same fixture and setup. After this initial pre-crushing, the specimens were unloaded, the fixture was opened, and a $15 \mathrm{~mm}$ spacer (made from the same laminate) was placed beneath the specimen, to achieve the original specimen height. The $\left[+45^{\circ} /-45^{\circ}\right]_{2 S}$ and $\left[+45^{\circ} / 0^{\circ}-45^{\circ} / 90^{\circ}\right]_{S}$ coupons with a pre-crushed trigger were then crushed in a similar way to the $\left[0^{\circ} / 90^{\circ}\right]_{2 S}$ coupons, where ply splaying again became increasingly predominant as the crushing progressed. With the pre-crushed trigger, no buckling instability was observed. 
(a)

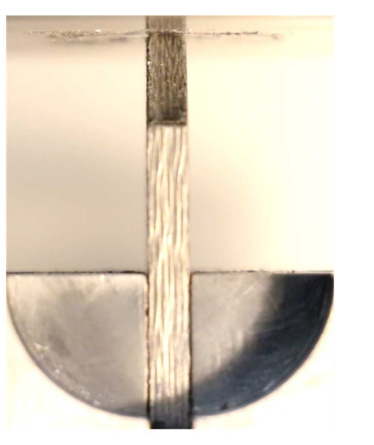

(c)

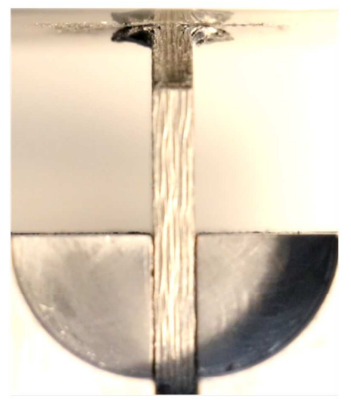

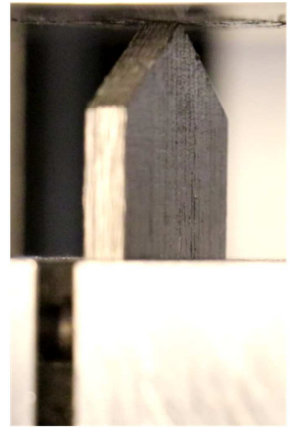

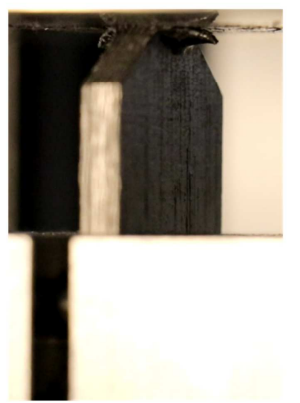

(b)

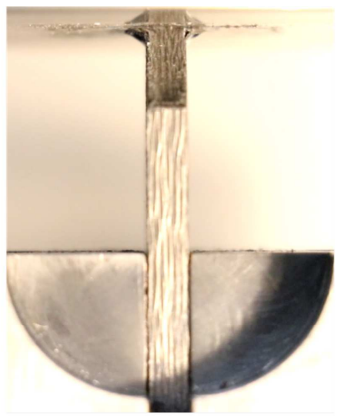

(d)

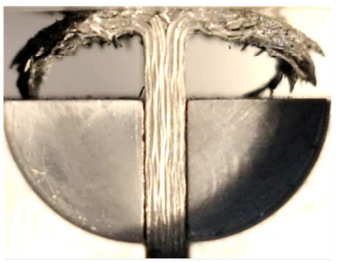

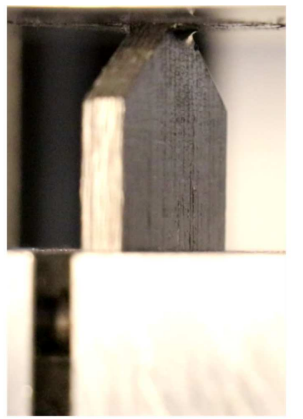

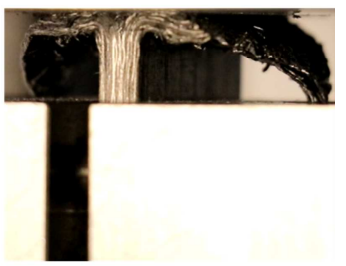

Figure 8 - Progressive quasi-static crushing of a $\left[0^{\circ} / 90^{\circ}\right]_{2 \mathrm{~s}}$ flat coupon: (a) start of the test; (b) outer ply bending and initial delaminations; (c) initial bending of the inner plies; (d) splaying of all plies with a central debris wedge.

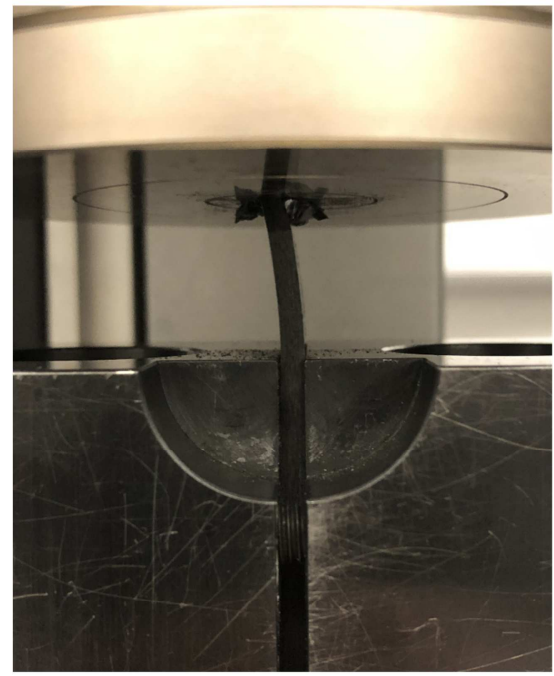

(a)

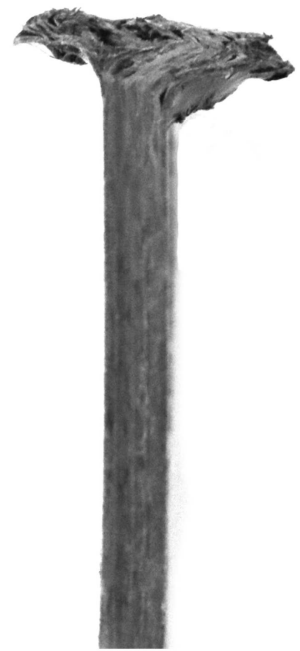

(b)

Figure 9 - (a) Buckling of the $\left[+45^{\circ} /-45^{\circ}\right]_{2 S}$ and $\left[+45^{\circ} / 0^{\circ} /-45^{\circ} / 90^{\circ}\right]_{S}$ flat coupons during quasi-static crushing; (b) asymmetric splaying due to buckling.

The stress during crushing, $\sigma$, was calculated from the load, $F$, divided by the full-width rectangular cross-sectional area, $A$. For these flat coupons, $A$ was equal to $72 \mathrm{~mm}^{2}$ (30 mm width, $2.4 \mathrm{~mm}$ thickness). The results for all coupons are presented in Figure 10.

The stress observed during the crushing of the $\left[0^{\circ} / 90^{\circ}\right]_{2 S}$ coupons showed a tendency to decrease as the crush progressed beyond the peak at the end of the trigger. Interestingly, the stress of the pre-crushed $\left[+45^{\circ} \%\right.$ 
$\left.45^{\circ}\right]_{2 \mathrm{~S}}$ and $\left[+45^{\circ} / 0^{\circ} /-45^{\circ} / 90^{\circ}\right]_{\mathrm{S}}$ coupons was, on average, higher than the one observed for the $\left[0^{\circ} / 90^{\circ}\right]_{2 \mathrm{~S}}$ coupons. The $\left[+45 \%{ }^{\circ} /-45^{\circ} / 90^{\circ}\right]_{\mathrm{s}}$ coupons also presented higher variability in results. A crush stress parameter, $\sigma_{C r}$, was calculated for the coupons of the different layups, in a constant cross-section crushing region. It was calculated as the average crush stress between the $10 \mathrm{~mm}$ and $17.5 \mathrm{~mm}$ displacement values (highlighted using dashed orange lines in Figure 10). These average crush stress values and their standard deviations are listed in Table 1.

It is not known whether steady-state crushing was achieved within the crushed coupon lengths, or whether a further reduction in crushing load would be observed with a coupon having a longer crushing length. Furthermore, as shown from similar crush coupon tests in literature [5,26], there is a tendency to either overestimate the crush stress parameter by having a short unsupported length which over-constrains the coupon, or to buckle the coupon by having a long unsupported length, as seen for two of the layups tested here. Future improvements should include testing significantly longer flat coupons in a test setup which allows the unsupported coupon length to remain constant throughout the test, by having the coupon slide out of the fixture to crush against a plate at a fixed distance, as suggested by Barnes [37]. This would help avoid the need of pre-crushing specimens, by allowing the unsupported length to be adjusted, and it would allow testing longer coupons where a plateau value of the crush stress could be more easily identified.

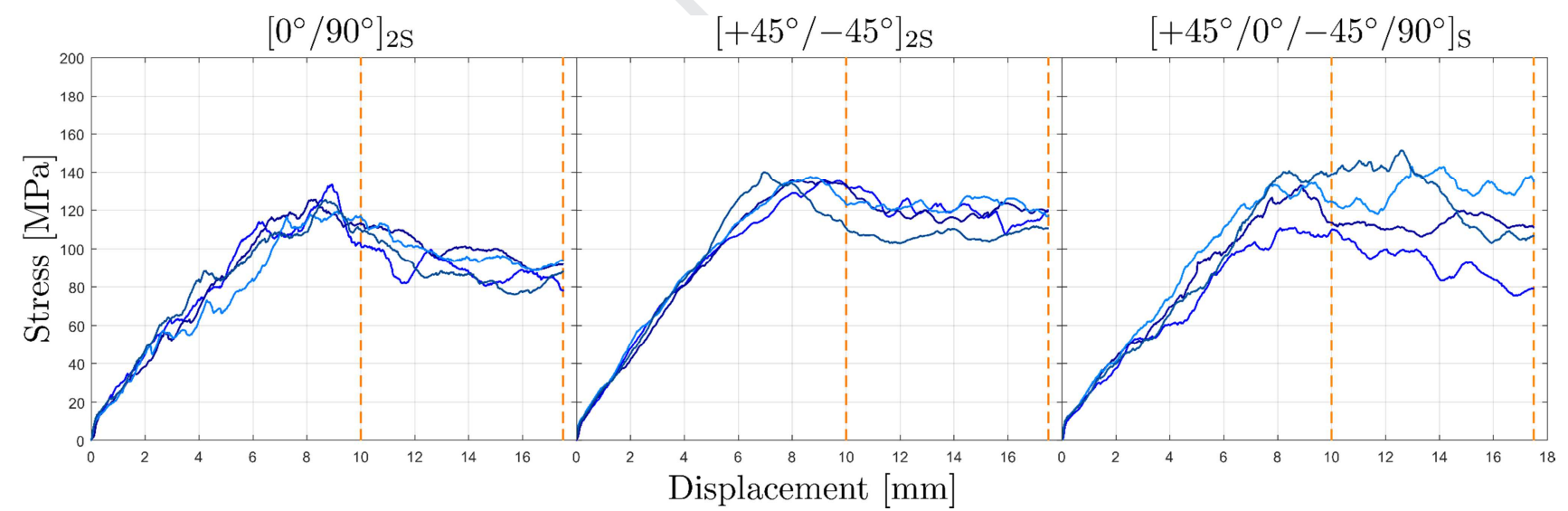

Figure 10 - Crushing stress for the quasi-statically tested flat coupons of the three layups. Dashed orange lines indicate the start and end of the region over which the crushing stress values were averaged.

Table 1 - Quasi-static averaged crush stress values for the flat coupons of the three different layups.

\begin{tabular}{ccc}
\hline Layup & Average crush stress $[\mathrm{MPa}]$ & Standard deviation $[\mathrm{MPa}]$ \\
\hline$\left[0^{\circ} / 90^{\circ}\right]_{2 \mathrm{~S}}$ & 93.7 & 9.2 \\
{$\left[+45^{\circ} /-45^{\circ}\right]_{2 \mathrm{~S}}$} & 117.9 & 6.75 \\
{$\left[+45^{\circ} / 0^{\circ}-45^{\circ} / 90^{\circ}\right]_{\mathrm{S}}$} & 118.0 & 18.9 \\
\hline
\end{tabular}


Quasi-static tubular coupons

The quasi-static $\left[0^{\circ} / 90^{\circ}\right]_{2 \mathrm{~S}}$ and $\left[+45^{\circ} / 0^{\circ} /-45^{\circ} / 90^{\circ}\right]_{\mathrm{S}}$ tubular coupons crushed in a stable progressive manner. The mode of crushing was very similar to the one observed in the flat coupons, where initial ply fragmentation developed a central debris wedge along the entire circumference of the tubes. The outer plies then proceeded to splay. A steady-state crushing process developed once all eight plies had splayed. The quasi-static $\left[+45^{\circ}-45^{\circ}\right]_{2 s}$ tubes did not crush progressively, and experienced a shear dominated failure away from the crash-front. Hence, the crushing results obtained for this layup were deemed invalid. A qualitative comparison of the quasi-static crushing for the four tubes for all three different layups is presented in Figure 11.

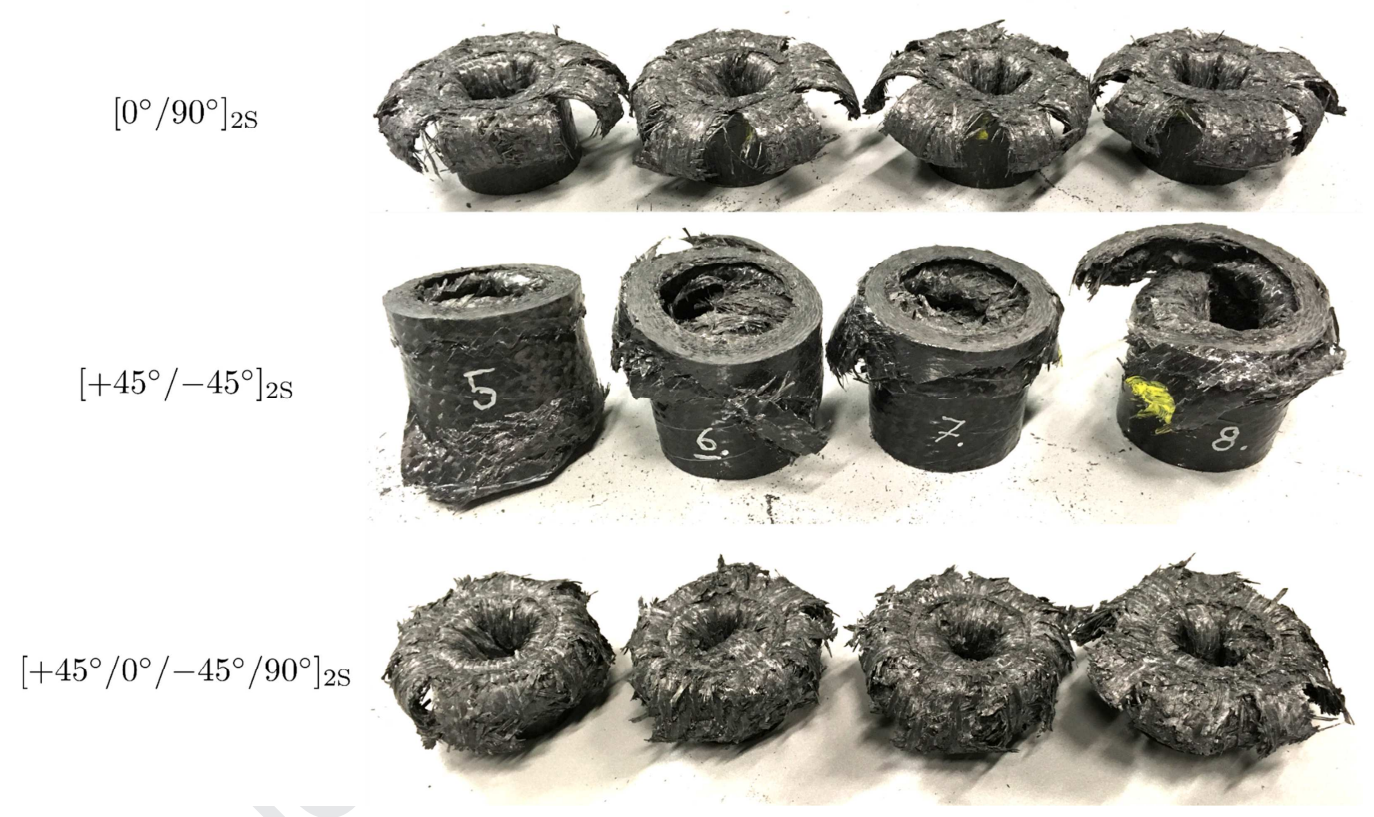

Figure 11 - Quasi-statically crushed tubular coupons for the three different layups.

The stress during crushing, for these tube specimens, was calculated in a similar way to the flat coupons, where the nominal cross-sectional area was equal to $A=\pi(D+t) t=259.4 \mathrm{~mm}^{2}$. These stresses are shown in Figure 12. The average values and standard deviations of these crush stresses, listed in Table 2, were calculated between crushing displacement values of $10 \mathrm{~mm}$ and $20 \mathrm{~mm}$ (highlighted in dashed orange lines in Figure $12 \mathrm{~b}$ ). The average quasi-static crush stress values obtained from the tubular coupons, for the $\left[0^{\circ} / 90^{\circ}\right]_{2 \mathrm{~S}}$ and $\left[+45 \%{ }^{\circ} /-45^{\circ} / 90^{\circ}\right]_{\mathrm{S}}$ layups, was on average $80 \%$ and $49 \%$ higher than the values obtained from the flat coupons, respectively. Furthermore, the average crush stress of the $\left[+45 \%{ }^{\circ} /-45^{\circ} / 90^{\circ}\right]_{S}$ tubes is slightly higher than that observed for the $\left[0^{\circ} / 90^{\circ}\right]_{2 s}$ tubes, similar to what was observed by Feraboli [6] for corrugated coupons. 


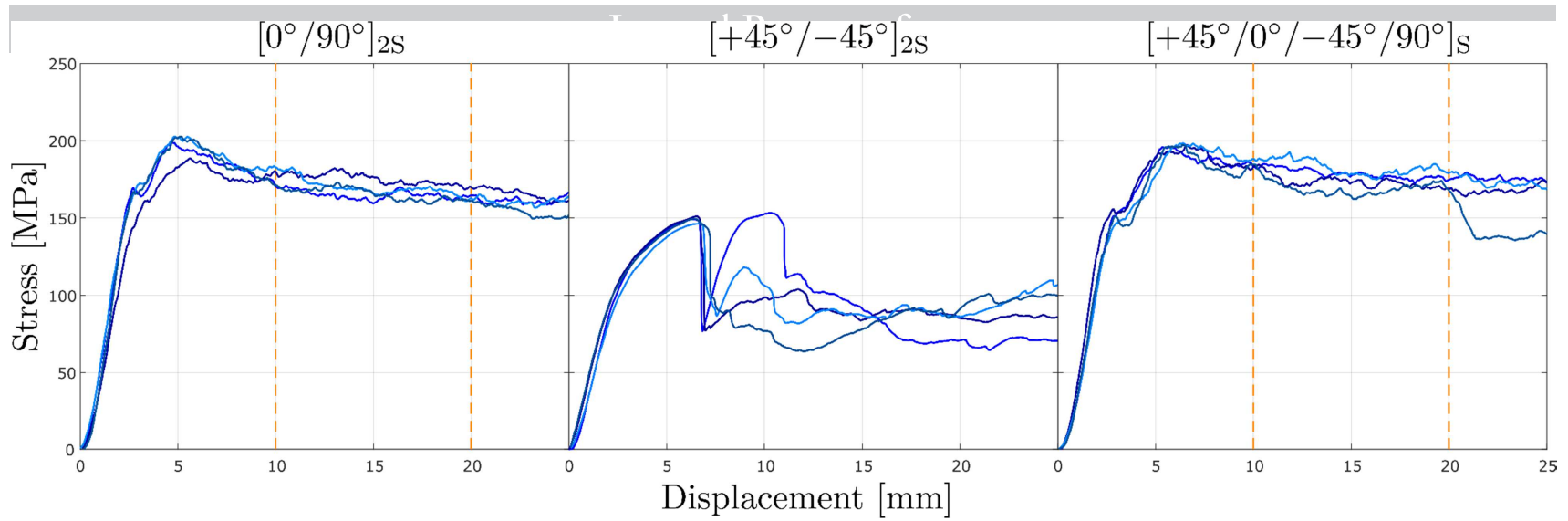

Figure 12 - Crushing stress for the quasi-statically tested tubular coupons of the three layups. Dashed orange lines indicate the start and end of the region over which the crushing stress values were averaged.

Table 2 - Quasi-static averaged crush stress values for the tubular coupons of the three different layups.

\begin{tabular}{ccc}
\hline Layup & Average crush stress $[\mathrm{MPa}]$ & Standard deviation $[\mathrm{MPa}]$ \\
\hline$\left[0^{\circ} / 90^{\circ}\right]_{2 \mathrm{~S}}$ & 169.0 & 5.8 \\
{$\left[+45^{\circ} /-45^{\circ}\right]_{2 \mathrm{~S}}$} & - & - \\
{$\left[+45^{\circ} / 0^{\circ} /-45^{\circ} / 90^{\circ}\right]_{\mathrm{S}}$} & 176.2 & 6.6 \\
\hline
\end{tabular}

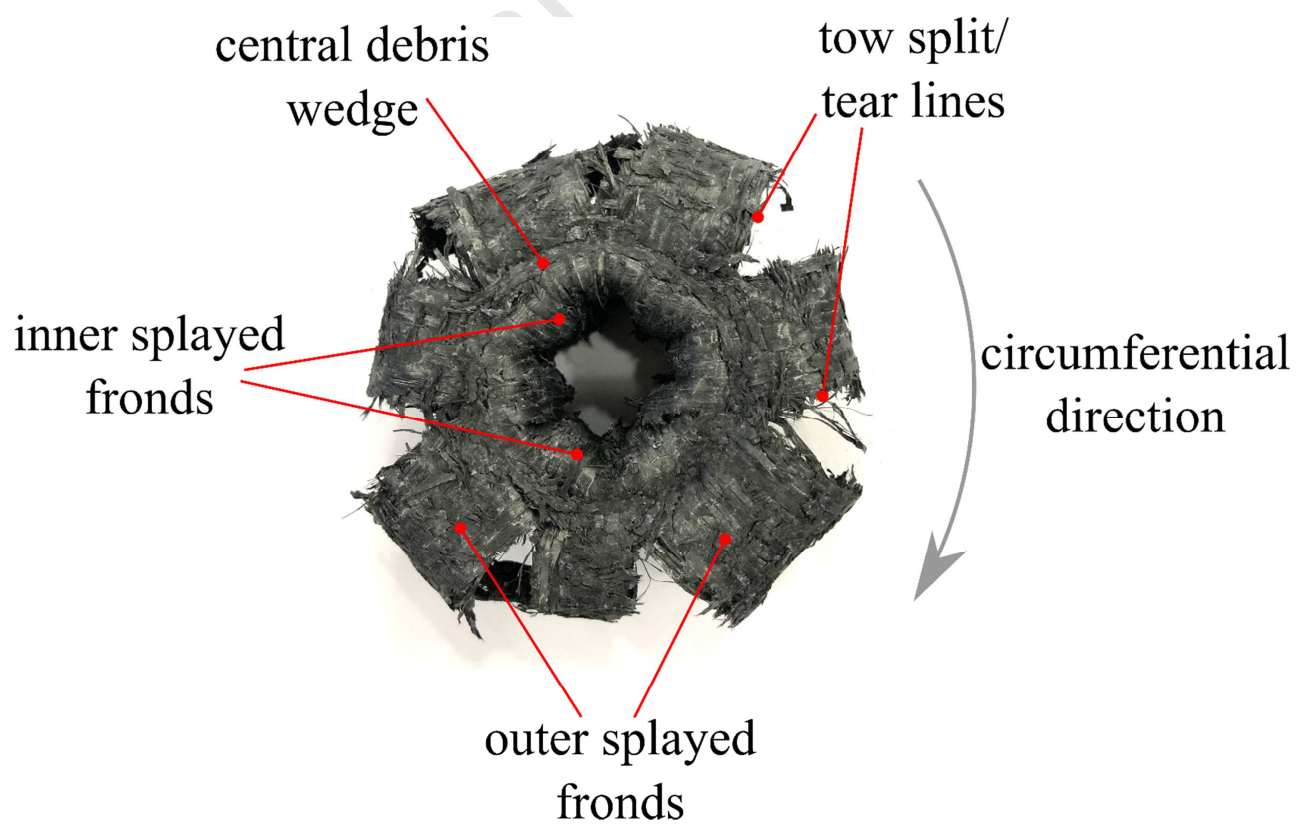

Figure 13 - Top view of a typical crushed $\left[0^{\circ} / 90^{\circ}\right]_{2 S}$ tubular coupon, highlighting the central debris wedge, tow split lines and the fronds that form between these split lines.

Although splaying was dominant in the crushing processes of both the flat and tubular coupons, the latter offered a greater resistance to the progressing crash-front. Unlike in the flat coupons, as the tubular crushing progressed and the plies splayed, the hoop stress in the fibre tows that were oriented circumferentially around 
the tubes, increased (as described in [36]). Thus, in order for the splaying to progress further, these tows needed to fracture, in tension for the outer splaying plies, and in compression for the plies splaying towards the centre of the tube. These splits occurred at multiple locations around the circumference of the tubes, causing tearing and forming several individual fronds, as shown in Figure 13. The plies splaying inwards also offered a further increase in energy absorption due to the extra friction generated, as the inner splaying fronds were forced to crush into each other.

Dynamic flat coupons

The dynamically tested $\left[0^{\circ} / 90^{\circ}\right]_{2 S}$ flat coupons crushed in a stable progressive manner, similar to their quasi-static counterparts. Splaying was again found to be the predominant damage mode once the crush progressed. Due to the instability observed during quasi-static crushing of $\left[+45^{\circ} /-45^{\circ}\right]_{2 s}$ and $\left[+45^{\circ} / 0^{\circ} /\right.$ $\left.45^{\circ} / 90^{\circ}\right]_{S}$ flat coupons, the same pre-crushing approach was adopted. These coupons were cut $15 \mathrm{~mm}$ short, pre-crushed under quasi-static loading, and then tested in the drop weight tower setup, with the $15 \mathrm{~mm}$ spacer beneath them in the fixture. The crush stress results for the three different layups are presented in Figure 14. There was a pronounced difference between the response of the $\left[0^{\circ} / 90^{\circ}\right]_{2 S}$ coupons and the pre-crushed $\left[+45^{\circ} /-45^{\circ}\right]_{2 \mathrm{~S}}$ and $\left[+45^{\circ} / 0^{\circ}-45^{\circ} / 90^{\circ}\right]_{\mathrm{S}}$ coupons. The overall trend of the crushing loads of the $\left[0^{\circ} / 90^{\circ}\right]_{2 \mathrm{~S}}$ coupons was similar to that observed for the quasi-static tests, albeit of a lower magnitude. A peak load was reached once the trigger had been completely crushed, and then the crushing load remained stable until the coupon was fully crushed and the impacting mass struck the fixture.

The load response for the $\left[+45^{\circ} /-45^{\circ}\right]_{2 \mathrm{~S}}$ and $\left[+45^{\circ} / 0^{\circ} /-45^{\circ} / 90^{\circ}\right]_{\mathrm{S}}$ flat coupons exhibited oscillatory responses, similar to what was observed by Lavoie et al. [4]. This could be attributed either to a dynamic instability of the coupons during crushing, movement or vibration of the fixture itself (since it was not clamped down on to the load cell), or a dynamic interaction between the testing machine and coupon. These oscillations could also reflect the material behaviour, with sudden progressive jumps in the delamination progression. Further studies need to be conducted on this method of dynamic flat coupon crushing, in order to understand whether the observed oscillations are a result of the coupon geometry or the experimental setup itself.

The average crush stress results for the three different layups, calculated in the same way as for the quasistatic tests, are listed in Table 3. The average stress of the $\left[0^{\circ} / 90^{\circ}\right]_{2 S}$ coupons was calculated after the trigger had been completely crushed, between $11 \mathrm{~mm}$ and $16 \mathrm{~mm}$ of crushing displacement. The limits of the regions over which the crush stress was averaged are highlighted using dashed orange lines in Figure 14. In this region, the crushing velocity decreased from around $5 \mathrm{~m} / \mathrm{s}$ to $4 \mathrm{~m} / \mathrm{s}$, as can be seen from the velocitydisplacement profile in Figure 15a. 


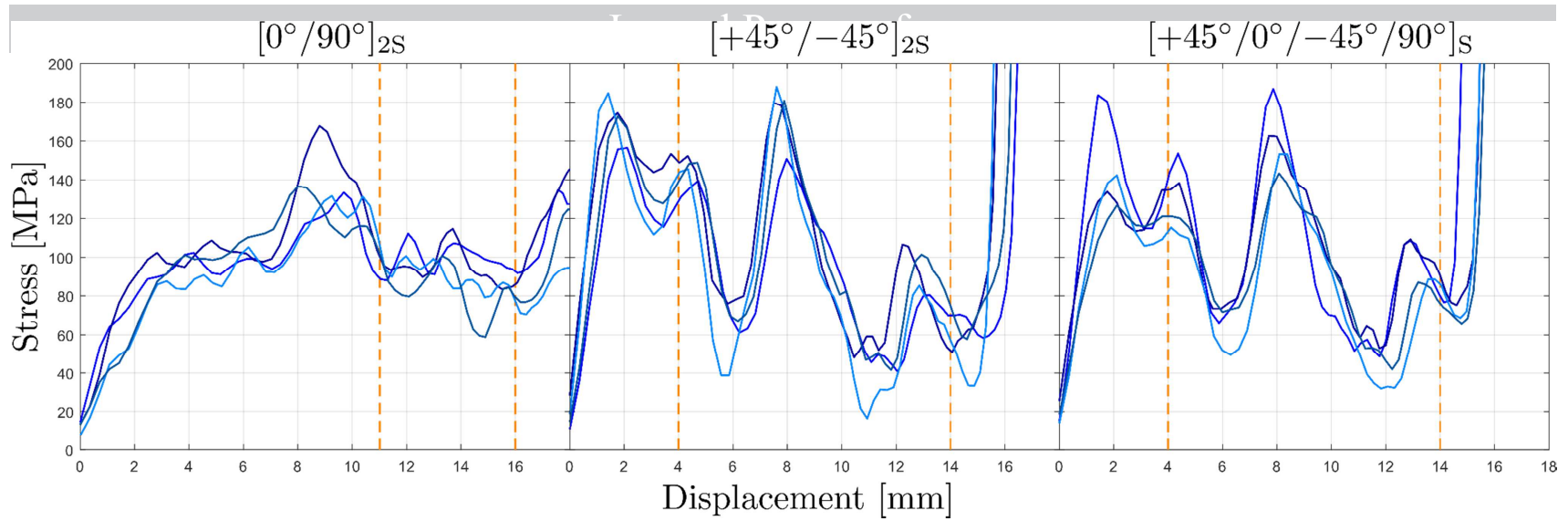

Figure 14 - Crushing stress for the dynamically tested flat coupons of the three layups. Dashed orange lines indicate the start and end of the region over which the crushing stress values were averaged.

For the other two layups, since the trigger had been pre-crushed, the average was taken between $4 \mathrm{~mm}$ and $14 \mathrm{~mm}$ of crushing displacement, after the initial load peak had been reached, and before the final load peak was reached, when the impacting mass came into contact with the fixture. In this region, the crushing velocity decreased from around $6 \mathrm{~m} / \mathrm{s}$ to $4 \mathrm{~m} / \mathrm{s}$, as can be seen from the velocity-displacement profile in Figure 15b. These crushing velocities are higher than the $1 \mathrm{~m} / \mathrm{s}$ threshold value mentioned by Feraboli [5], for which the crushing behaviour is said to transition from quasi-static to dynamic.

The average dynamic crush stresses obtained from these flat coupons seems to be similar for all the three different layups, yet the standard deviation is significantly higher for the $\left[+45^{\circ} /-45^{\circ}\right]_{2 \mathrm{~s}}$ and $\left[+45^{\circ} / 0^{\circ} /-45^{\circ} / 90^{\circ}\right]_{\mathrm{s}}$ coupons, due to the aforementioned oscillations. Furthermore, these results suggest there is an almost negligible $3 \%$ decrease in the energy absorption capability of the flat $\left[0 \% 190^{\circ}\right]_{2 S}$ coupons when tested dynamically, compared to the quasi-static values. A more significant $22-23 \%$ decrease was observed for the other two layups, when tested dynamically.

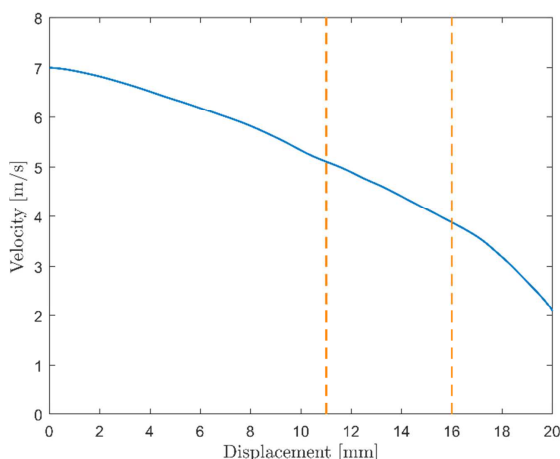

(a)

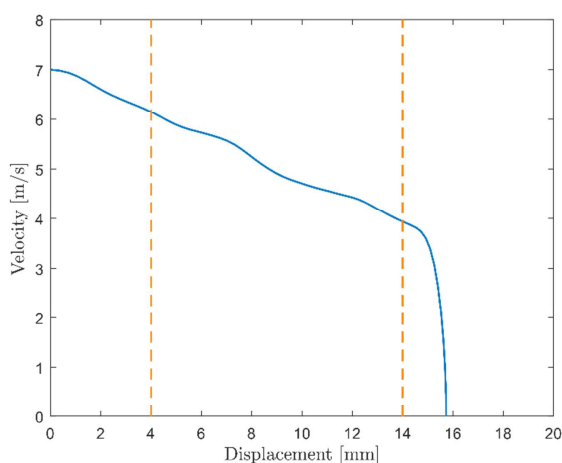

(b)

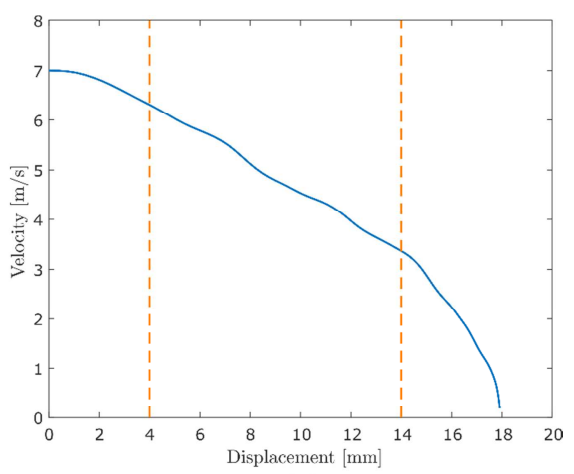

(c)

Figure 15 - Representative velocity-displacement profiles for a dynamic crush test of a: (a) $\left[0^{\circ} / 90^{\circ}\right]_{2 \mathrm{~S}}$ flat coupon; (b) $\left[+45^{\circ} / 0^{\circ}\right.$ $\left.45^{\circ} / 90^{\circ}\right]_{\mathrm{S}}$ flat coupon; (c) $\left[0^{\circ} / 90^{\circ}\right]_{2 \mathrm{~S}}$ tubular coupon. Dashed orange lines indicate the start and end of the region over which the crushing stress values were averaged. 
Table 3 - Averaged crush stress values for the dynamically tested flat coupons of the three different layups.

\begin{tabular}{ccc}
\hline Layup & Average crush stress $[\mathrm{MPa}]$ & Standard deviation $[\mathrm{MPa}]$ \\
\hline$\left[0^{\circ} / 90^{\circ}\right]_{2 \mathrm{~S}}$ & 91.0 & 11.0 \\
{$\left[+45^{\circ} /-45^{\circ}\right]_{2 \mathrm{~S}}$} & 90.9 & 38.8 \\
{$\left[+45^{\circ} / 0^{\circ} / 45^{\circ} / 90^{\circ}\right]_{\mathrm{S}}$} & 93.0 & 34.0 \\
\hline
\end{tabular}

\section{Dynamic tubular specimens}

The dynamic $\left[0^{\circ} / 90^{\circ}\right]_{2 S}$ and $\left[+45^{\circ} / 0^{\circ} / 45^{\circ} / 90^{\circ}\right]_{S}$ tubular coupons crushed in a progressive manner, where qualitatively, the mode of crushing was very similar to the one observed for their quasi-static counterparts. Unlike what was observed quantitatively for the quasi-static tube tests, the $\left[+45^{\circ} /-45^{\circ}\right]_{2 s}$ tubular coupons also crushed in a stable manner, similar to the other two dynamically tested layups. The similarity was observed both visually, from the splayed fronds, and quantitatively, from the crushing stress responses, as seen in Figure 16. All the dynamic tubular coupons exhibited an oscillatory crushing response, as evidenced in Figure 16. Although these oscillations were of a smaller magnitude than the dynamic oscillations observed from the $\left[+45^{\circ} /-45^{\circ}\right]_{2 \mathrm{~S}}$ and $\left[+45^{\circ} / 0^{\circ} /-45^{\circ} / 90^{\circ}\right]_{S}$ flat coupons, their value is still substantial. These oscillations, similar to what was reported by Reuter et al. [38], could either be a result of the dynamic experimental setup, as hypothesised from the flat coupon results, or they could arise from sudden circumferential fibre tow splits, discussed previously, that lead to a sudden jump in the delamination fronts and splaying progression.

The average crush stress for these coupons was calculated using the same nominal cross-section of the quasi-static tubes. The average and standard deviation of the crush stress, listed in Table 4 for all three layups, was calculated over a crushing distance of $10 \mathrm{~mm}$, between the $4 \mathrm{~mm}$ and $14 \mathrm{~mm}$ positions indicated in Figure 16. These positions equated to crushing velocities of around $6.5 \mathrm{~m} / \mathrm{s}$ and $3.5 \mathrm{~m} / \mathrm{s}$, respectively, as shown from the velocity-displacement profile of Figure 15c for a typical tubular coupon test.

Table 4 - Averaged crush stress values for the dynamically tested tubular coupons of the three different layups.

\begin{tabular}{ccc}
\hline Layup & Average crush stress $[\mathrm{MPa}]$ & Standard deviation $[\mathrm{MPa}]$ \\
\hline$\left[0^{\circ} / 90^{\circ}\right]_{2 \mathrm{~S}}$ & 135.3 & 34.3 \\
{$\left[+45^{\circ} /-45^{\circ}\right]_{2 \mathrm{~S}}$} & 134.4 & 32.4 \\
{$\left[+45^{\circ} / 0^{\circ}-45^{\circ} / 90^{\circ}\right]_{\mathrm{S}}$} & 138.6 & 29.7 \\
\hline
\end{tabular}

The average dynamic crush stresses obtained from these tubular coupons is quite similar for all the three different layups. The standard deviations are significantly higher than those of the quasi-static tubular coupons, due to the large load oscillations. Under dynamic loading, a decrease in average crushing stress of $20 \%$ and $21 \%$ was observed for the $\left[0^{\circ} / 90^{\circ}\right]_{2 S}$ and $\left[+45^{\circ} / 0^{\circ}-45^{\circ} / 90^{\circ}\right]_{S}$ tubular coupons, respectively. 


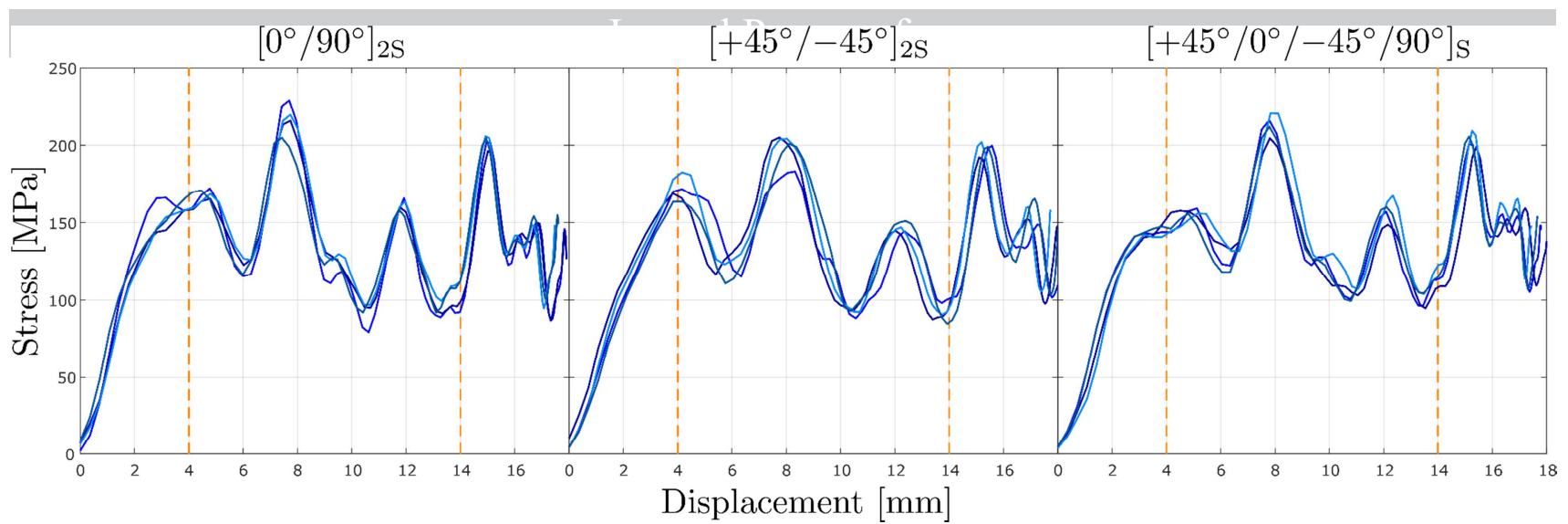

Figure 16 - Crushing stress for the dynamically tested tubular coupons of the three layups. Crush stress average value calculated in the region between the dashed orange lines.

\subsubsection{Side Impact Structures}

Quasi-static

All three quasi-static (QS) SISs crushed in a stable progressive manner, where both splaying and ply fragmentation were observed. The sequential crushing process is presented in Figure 17, at intervals of $50 \mathrm{~mm}$ of crushing displacement. The crushed SISs were then sectioned for post-mortem analysis. Due to the curved closed-section geometry, outward and inward ply splaying was restricted by the circumferential fibre tows, which resisted the hoop stresses in a similar manner to the tubular coupons. The progressive splaying eventually produced large tearing, after circumferential tows were forced to split, principally along the axial lines which separated the flat and curved portions of the structure, highlighted in dashed black lines in Figure 18. Large fronds formed between these tear/split lines, shown after a completed crush test in Figure 19a. Tow splitting/tearing also occurred along the vertical edges of the inner rib structure due to asymmetric splaying of the outer envelope plies (unequal number of plies splayed inwards and outwards), as can be observed in Figure 19a.

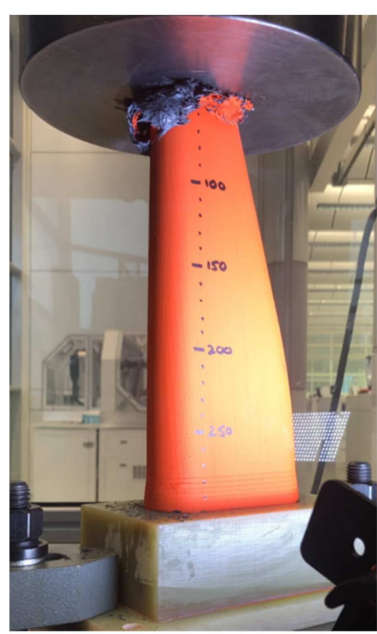

$50 \mathrm{~mm}$

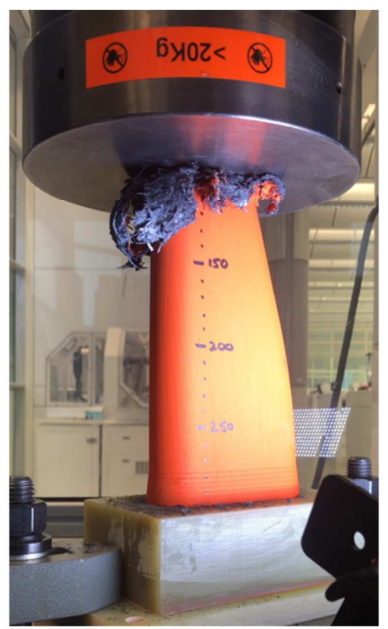

$100 \mathrm{~mm}$

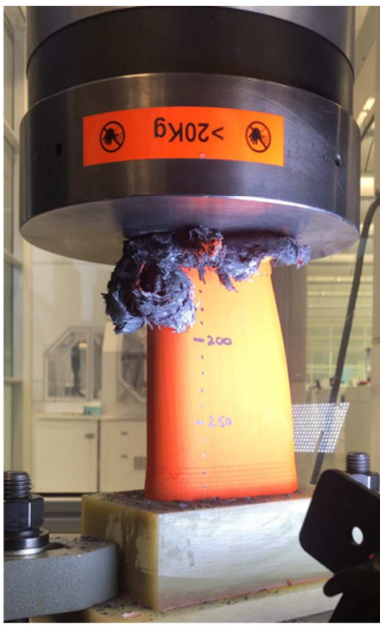

$150 \mathrm{~mm}$

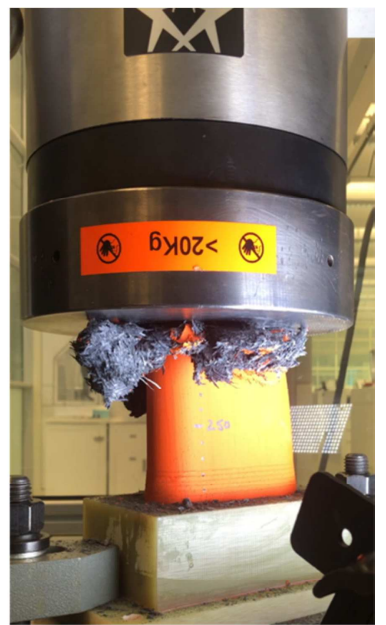

$200 \mathrm{~mm}$

Figure 17 - Experimental progression of the quasi-static crushing of a Side Impact Structure, in $50 \mathrm{~mm}$ steps of crushing displacement. 


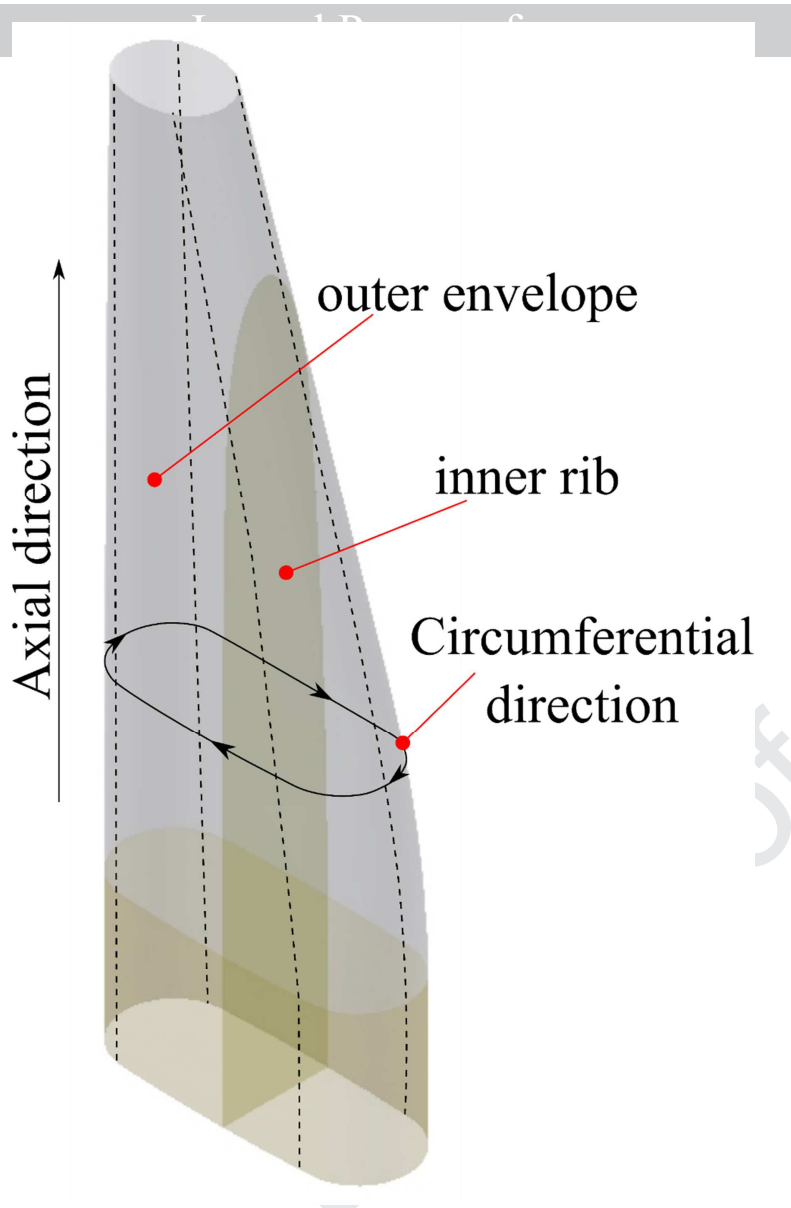

Figure 18 - Axial paths of changing curvature along the Side Impact Structure, shown using dashed black lines. The axial and circumferential directions of the SIS are also indicated. The inner rib and outer envelope sections are identified.

As all the outer 6 plies were splayed outwards, the inner rib was split/torn from these adjoining plies, as shown in Figure 19a. Once these major split lines were formed, the fronds of the flat and curved portions of the outer envelope sections splayed progressively. Furthermore, the inner rib became unsupported on both sides, and was forced to bend and splay. The curved nature of the SIS, together with the large amount of debris created at the crash-front, promoted asymmetric ply splaying, unlike what was observed in the flat and tubular coupons.

Even though a significant amount of debris was found compacted internally when sectioning the crushed SISs, the crash-front at the end of the tests exhibited outward ply splaying. Figure $19 \mathrm{~b}$ and Figure $19 \mathrm{c}$ present cross-sections of both the curved and flat regions of the crushed SIS, respectively, where the laminate splayed entirely outwards. This asymmetry is an indication that the crushing behaviour of the flat and curved regions of the SIS, and consequently the overall crushing efficiency, could be significantly different than that observed for the symmetrically splayed flat and tubular coupons (equal number of inward and outward splayed plies), alluding to the lack of geometric scalability of crashworthiness discussed in literature $[13,17]$. Chambe et al. [23] showed that for tubular CFRP coupons, outward splaying of the entire laminate results in a decrease in crush efficiency (up to $20 \%$ when compared to symmetric splaying), since inward splaying plies would offer more energy absorption due to the friction between the fronds that form. 


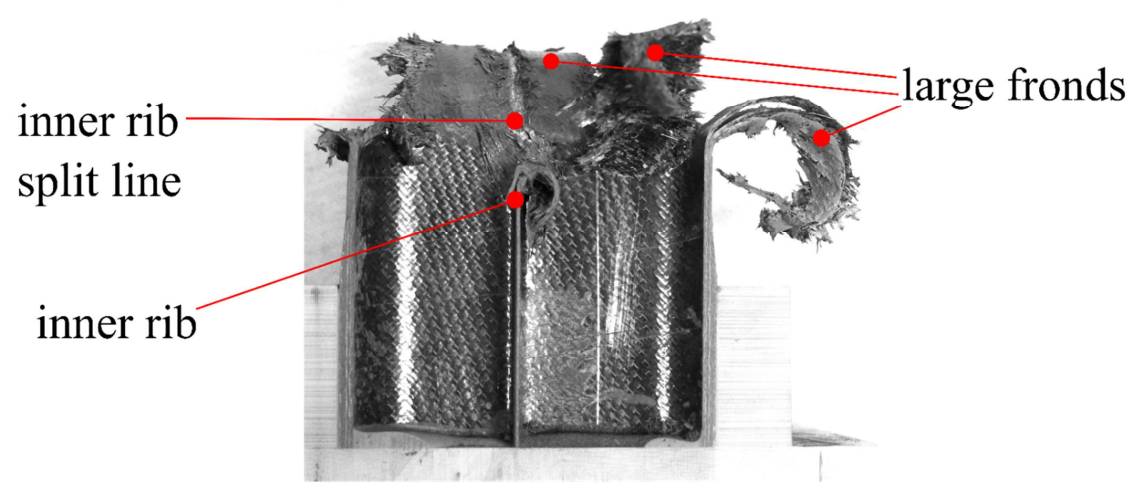

(a)

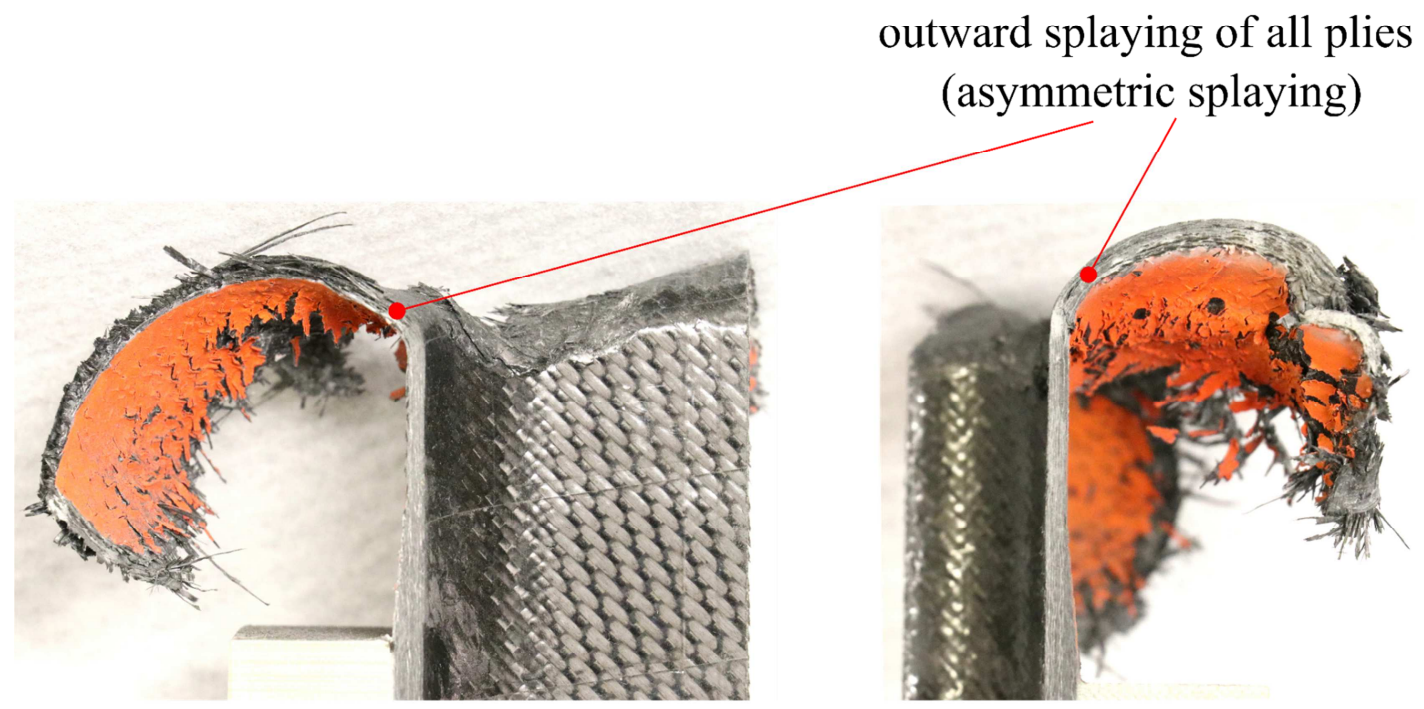

(b)

(c)

Figure 19 - Sections of a quasi-statically crushed Side Impact Structure: (a) half-section; (b) quarter-section in the middle of a curved region; (c) quarter-section in the middle of a flat region.

The crushing load responses of the three tested SISs are presented in Figure 20b. The lack of a sharp peak load upon the initiation of crushing shows that this structural design is suitable for use as a crash structure, as it will crush progressively. This has been achieved through the non-uniform increasing cross-sectional area of the SIS, which promotes failure at the small front end. All three responses are shown to be quite similar. A significant load drop to $35 \mathrm{kN}$ was noted for the $3^{\text {rd }}$ SIS (QS-3) at a cross-head displacement of $140 \mathrm{~mm}$. However, this SIS test was halted numerous times, and the structure was unloaded to take pictures, then reloaded and the test continued. The observed load drop was due to a visible localised buckling failure of some outer plies, which occurred just after reloading the structure. The other two SIS tests were loaded continuously up to $250 \mathrm{~mm}$ of crushing, and did not show any sign of unwanted failures. Hence, the load drop of QS-3 SIS was attributed to the unloading/reloading of the structure during crushing, which could have caused stress redistributions resulting in the buckling failure. 
The stress during these crushing tests was calculated using the cross-sectional area obtained from the CAD model of the SIS. This variation in cross-sectional area is presented in Figure 20a, and the corresponding stress during crushing in Figure 20c.

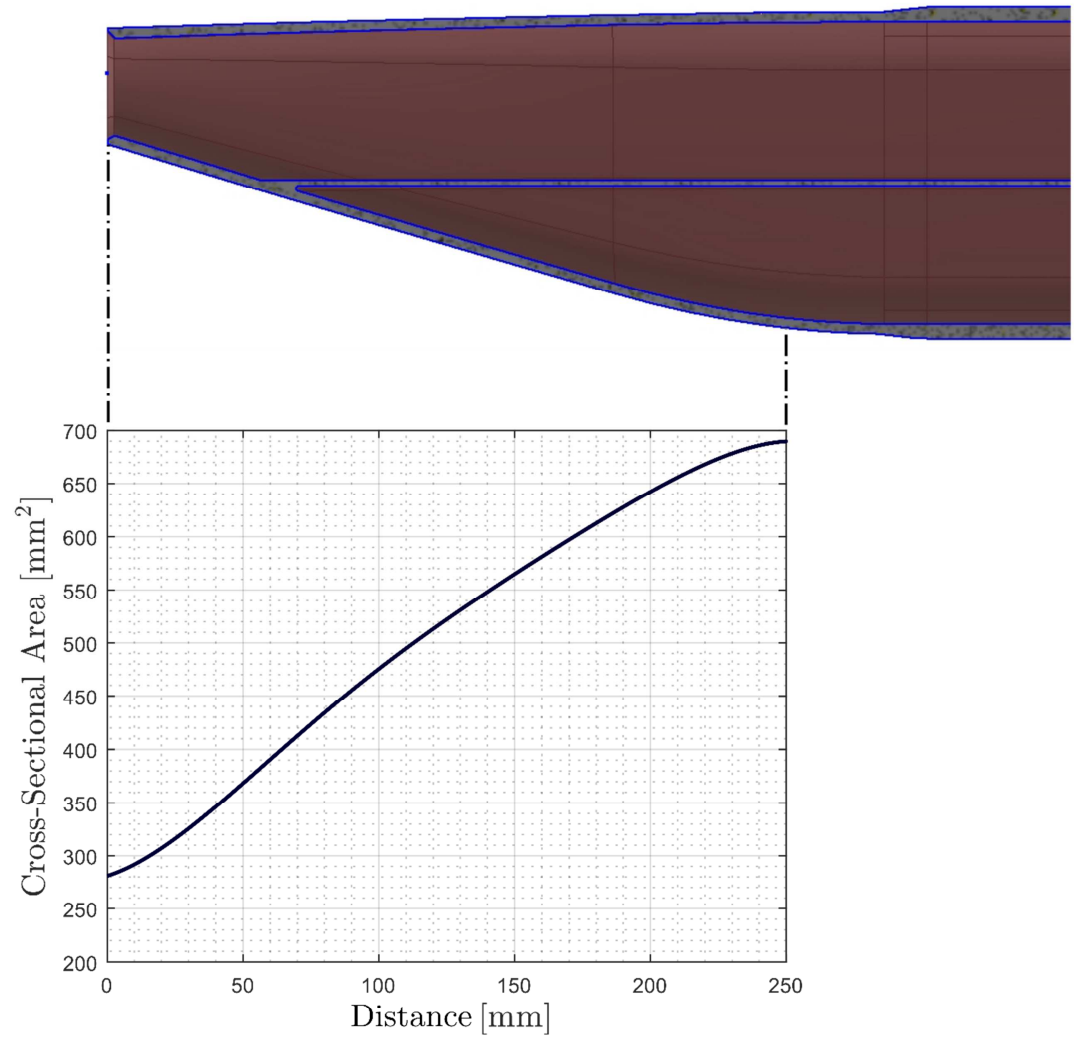

(a)

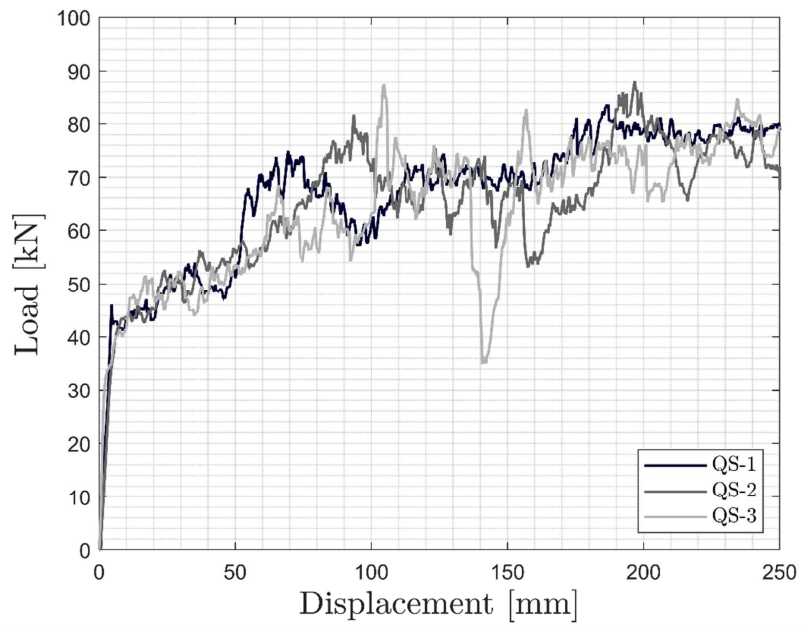

(b)

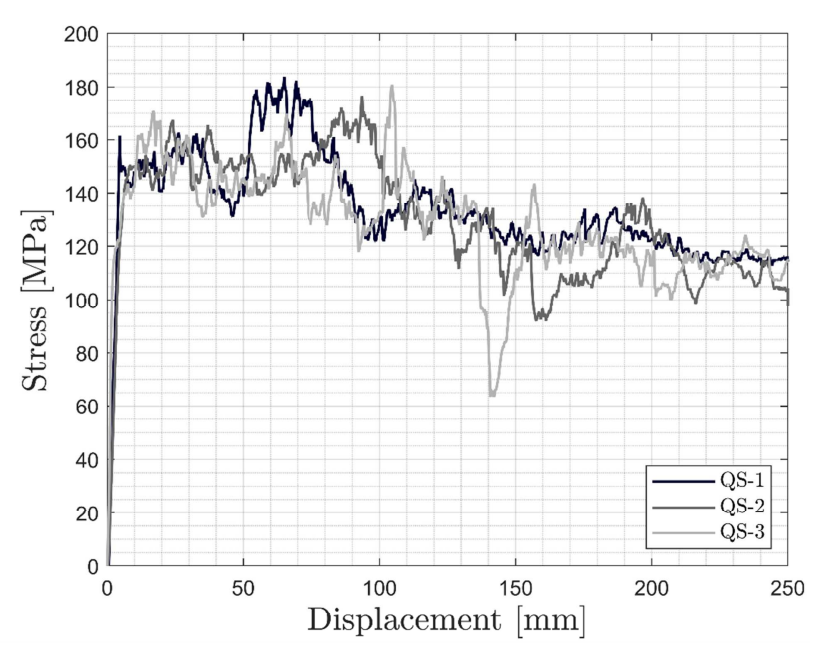

(c)

Figure 20 - (a) Variation in cross-sectional area of the Side Impact Structure (SIS); (b) crushing load for three SISs tested under quasi-static (QS) loading; and (c) their corresponding stress calculated using the varying cross-sectional area.

Figure 20c shows a progressive decrease in crushing stress. The varying curvature of the SIS is the likely reason for this decrease. The SIS geometry changes from mostly curved at the top end, to include two large flat regions in between the curved sections further down. The inner rib, starting from $70 \mathrm{~mm}$ of crushing, is 
also a flat region. As seen from the flat and tubular coupon tests, curvature results in an increased crushing stress. This corroborates the gradual reduction in the crushing stress observed throughout the crushing of the SIS. The crush stress shown in Figure 20c varies from around 140-180 MPa at the start of the SIS, where a significant portion of the cross-section possesses curvature, to around 100-120 MPa at $250 \mathrm{~mm}$ of crushing, where the SIS cross-section includes two large flat regions (and a flat internal rib). These values are quite similar to the 176.2 $\mathrm{MPa}$ and 118.0 $\mathrm{MPa}$ crush stress values obtained from the quasi-static tubular and flat coupon tests, respectively. Even if at $250 \mathrm{~mm}$ of crushing, the SIS still includes two curved sections which are being crushed, the dominant outward splaying observed in Figure 19b could justify why these regions are offering a lower crush resistance than the tested tubular coupons, due to the reduced friction described earlier.

The specific energy absorption of a structure over its entire crushing length, $s$, can be calculated using:

$$
S E A=\frac{1}{m} \int F d s
$$

Considering the total crushed mass, $m$, of the SIS to be $0.203 \mathrm{~kg}$, the average quasi-static SEA is equal to $81.75 \mathrm{~kJ} / \mathrm{kg}$.

Dynamic

Electronic version: The dynamic (DYN) crushing process of the two SISs is presented from a lateral perspective in the following video.

Print version: Figure 21 is a still frame taken from a video that captured the dynamic (DYN) crushing process of the two SISs (from a lateral perspective), which is available in the electronic version of this article. The still was taken at around $100 \mathrm{~mm}$ of crushing displacement.

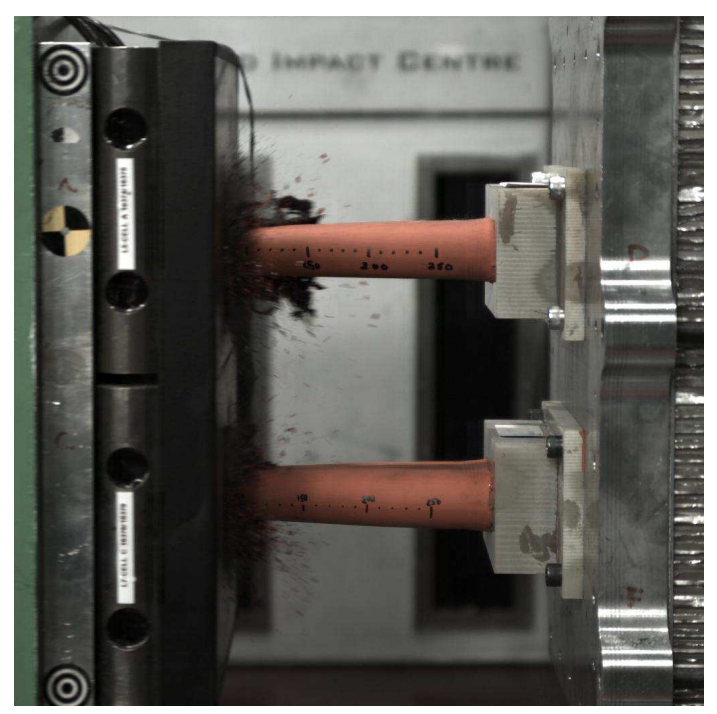

Figure 21 - Still from Video 1 of the dynamic crushing process of two Side Impact Structures, at $100 \mathrm{~mm}$ of crushing displacement. Video 1 - Progression of the dynamic crushing process of two Side Impact Structures. 
Large delaminations were observed from the post-mortem analysis, presented in Figure 22d. These significant delaminations allowed the individual plies to fold, rather than being forced to crush. Some of the delaminated plies were then compacted inwards, as shown in Figure 22b. After removing this compacted material, it was observed that the axial splitting lines were also present in these dynamically crushed tubes, similar to what was observed quasi-statically. These split lines, including the ones arising from the inner rib, divide the large fronds from each other, and can be observed in Figure 22a,c.

The load responses of the two dynamic tests are presented in Figure 23a, overlaid on the three quasi-static results. Similar to what was observed quasi-statically, there is no significant load peak, and the load responses of both dynamic tests show good repeatability. However, once the outboard ends of the SISs started to crush, there was a decrease in the load of the dynamic tests when compared to the quasi-static results, throughout the entire $250 \mathrm{~mm}$ of crushing, with a commensurate lower crushing stress, presented in Figure 23b. Over the first $250 \mathrm{~mm}$ of crushing, the velocity of the impacting mass decreased from approximately $10 \mathrm{~m} / \mathrm{s}$ to $5 \mathrm{~m} / \mathrm{s}$, as shown in the experimental velocity-displacement profile of Figure 26.

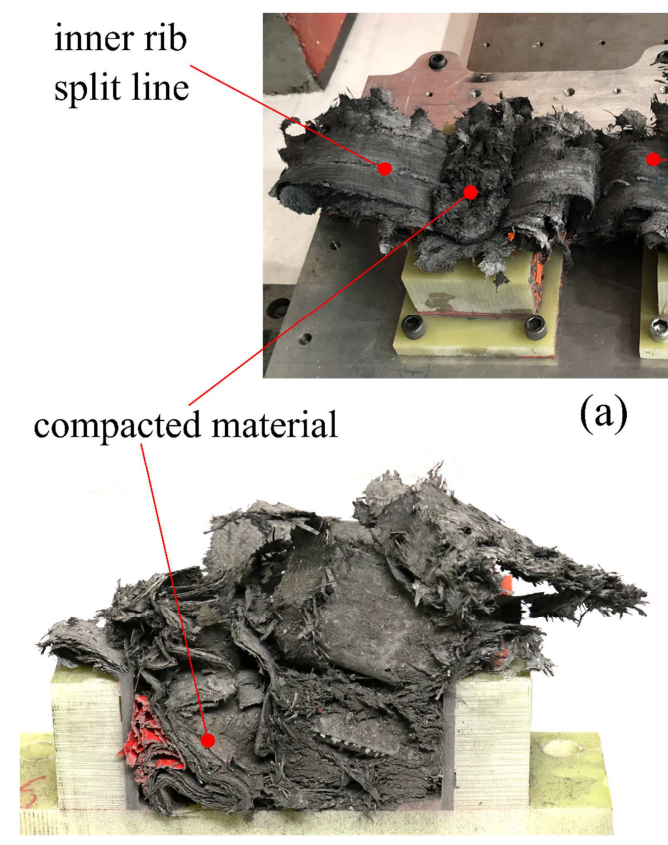

(b) (a)

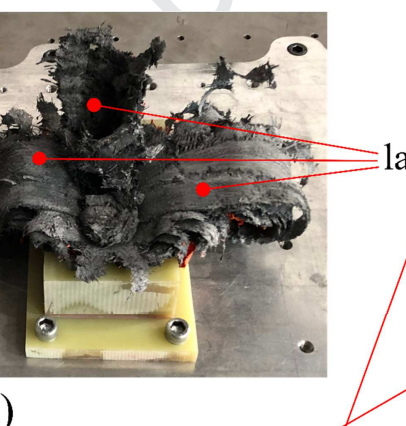
split lines

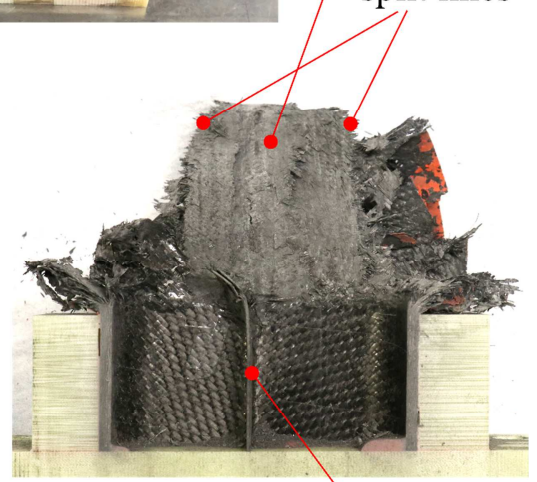

(c)

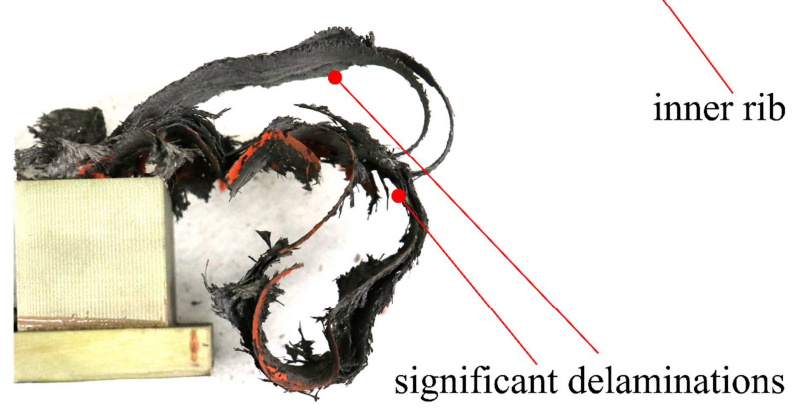

(d)

Figure 22 - Dynamically crushed Side Impact Structure (SIS): (a) two mounted SISs after the test; (b) half-section of a SIS with compacted material inside; (c) same half-section but with the compacted material removed; (d) side view of the half-section, highlighting a number of significantly delaminated plies. 


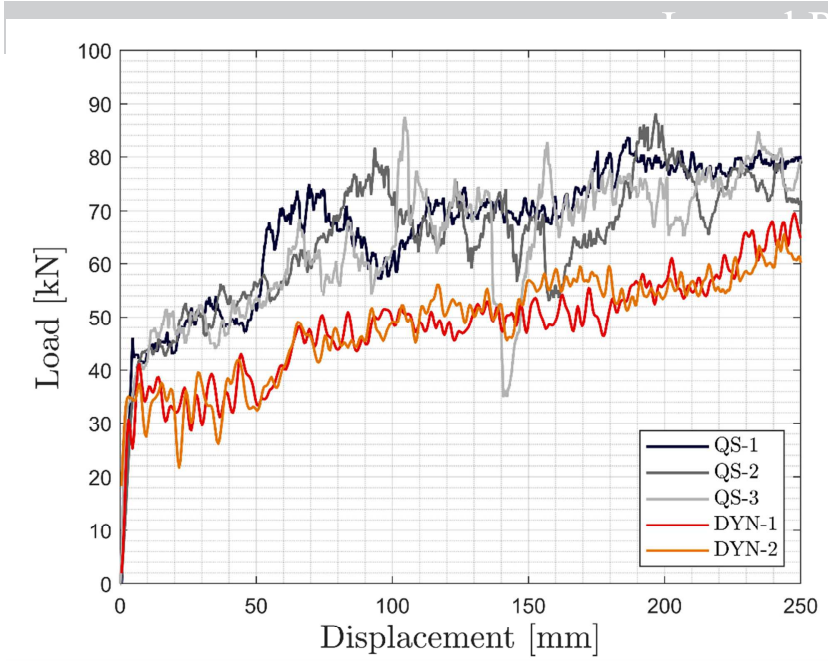

(a)

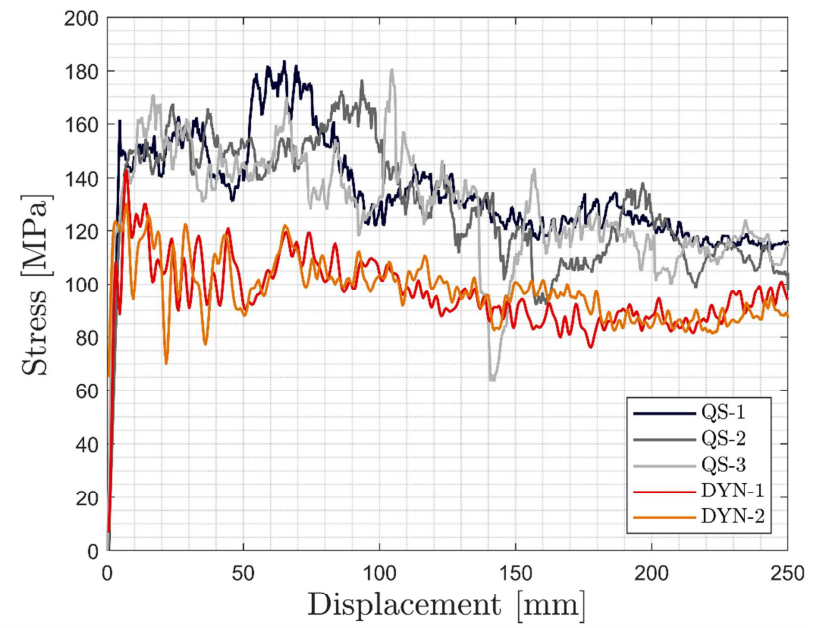

(b)

Figure 23 - (a) Crushing load; and (b) corresponding stress for two dynamically tested (DYN) Side Impact Structures, overlaying the three quasi-static (QS) results of Figure 23.

The crush stress results of Figure $23 \mathrm{~b}$ indicate a progressive decrease in crush stress, similar to the quasistatic results. The dynamic crush stress varied from approximately 100-140 MPa at the start of the crush, to around 80-100 MPa at $250 \mathrm{~mm}$ of crushing. These values are quite similar to the 138.6 MPa and 93.0 MPa crush stress values obtained from the dynamic tubular and flat coupon tests, respectively.

Considering the same total crushed mass of $0.203 \mathrm{~kg}$ as the quasi-static tests, the average dynamic specific energy absorption of these structures is equal to $60.07 \mathrm{~kJ} / \mathrm{kg}$. This equates to a $26.5 \%$ decrease in $S E A$ from the quasi-static structures, which can be mostly attributed to the larger amount of delaminations observed in the dynamic experiments, which allowed the individual plies to fold rather than to crush.

\section{Numerical simulation of the macroscopic crushing process}

Motivated by the low computational cost and modern techniques available for modelling the crushing behaviour of composites, this section presents a numerical methodology to simulate both quasi-static and dynamic crushing responses of the SIS, at the macro-scale, i.e. considering the entire structure as a homogeneous part, consequently not modelling interlaminar regions explicitly.

The crush simulations are conducted by coupling an Abaqus ${ }^{\circledR}$ in-built constitutive material model with an Abaqus ${ }^{\circledR}$ plugin named CZone. For the sake of completeness, the following sub-sections describe both the material model and the add-on. The simulations were conducted using the FE solver Abaqus ${ }^{\circledR} /$ Explicit [30], and they ran on one node (1 CPU @ $3.4 \mathrm{GHz}$ of Intel ${ }^{\circledR}$ Haswell ${ }^{\circledR}$ ) having 512 GB of RAM. The results presented in this section constitute the quantitative responses of the quasi-static and dynamic loading conditions and allow for a direct comparison with the experimental results described above. 


\subsection{Constitutive model}

\subsubsection{Material response}

An Abaqus ${ }^{\circledR}$ in-built orthotropic constitutive material damage model, suitable for modelling damage in 2D woven composites, was used to describe the material behaviour of the SIS. This model, implemented as a VUMAT subroutine, can be accessed by using a material name string such as ABQ_PLY_FABRIC [30]. This material model is based on Continuum Damage Mechanics (CDM), and was developed for the calculation of the initiation and propagation of laminate-level damage of 2D woven composite materials [31].

The entire laminate was modelled by a single shell element through-thickness, and consequently, interlaminar damage, i.e. delamination, was not considered here. This material model was previously used by other researchers, who successfully managed to simulate the crushing behaviour of this type of material $[39,40]$. It assumes a linear-elastic response up to failure for fibre-dominated damage, i.e. in the longitudinal and transverse directions, where the loading functions take the form of a maximum stress criteria and an energy-based damage evolution law. To ensure mesh size independency, for the two fibre directions under uniaxial tensile and compressive loading, the computed energy dissipation was regularised using the corresponding fracture toughness values of the material, and the associated characteristic element length [41]. For in-plane shear, an elastic-perfectly plastic response was assumed, where a classical plasticity model was used with an elastic domain function and a hardening law which was applied to the effective stress tensor, i.e. the stress tensor calculated using the undamaged stiffness tensor. Damage initiation under in-plane shear was also captured using a maximum stress criterion. Damage propagation was captured using a degradation parameter, similar to that used for the longitudinal and transverse directions. However, it is important to note that this model does not include regularisation of energy dissipation under in-plane shear loading, since shear softening is not considered. Thus, no input was required for the mode II intralaminar fracture toughness. For more details on this damage model, the reader is referred to $[31,39]$.

\subsubsection{CZone}

The constitutive material model was combined with the CZone add-on for Abaqus ${ }^{\circledR} /$ Explicit [30], making use of a user-defined field, i.e. a VUSDFLD, in order to model the crushing behaviour of the elements at the crash-front. CZone requires the input of crush stress parameter data, which was shown to be a structural property influenced by ply orientations, coupon geometry, and crushing velocity. Figure 24 summarises the contribution of the CZone add-on to the element behaviour in the numerical simulations. 


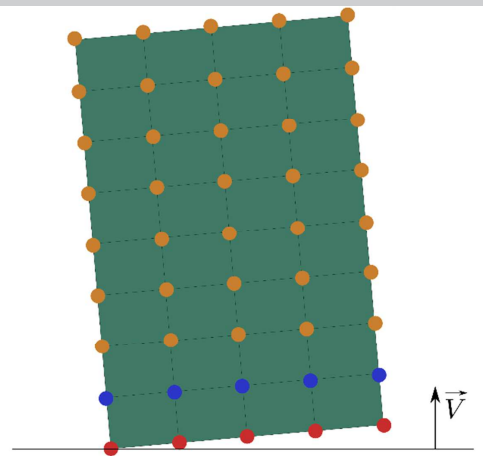

(a)

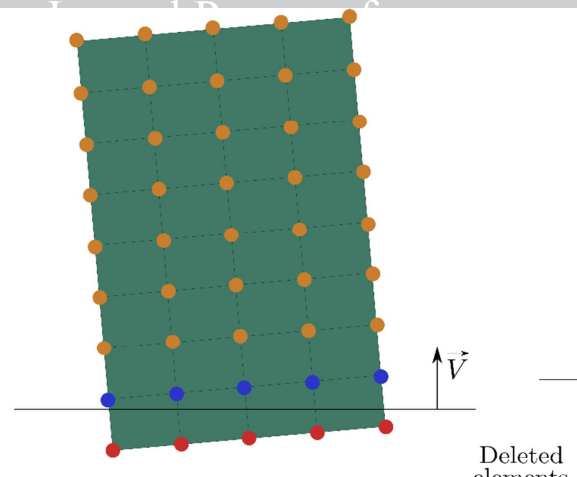

(b)

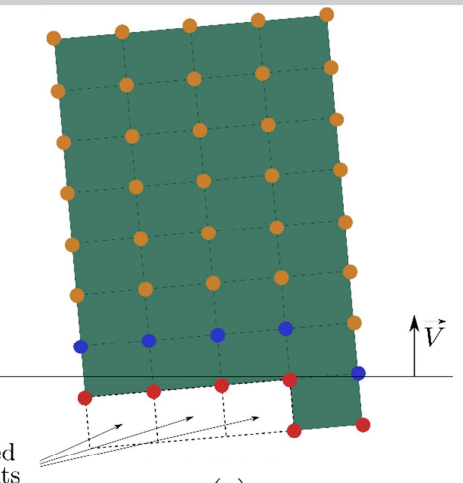

(c)

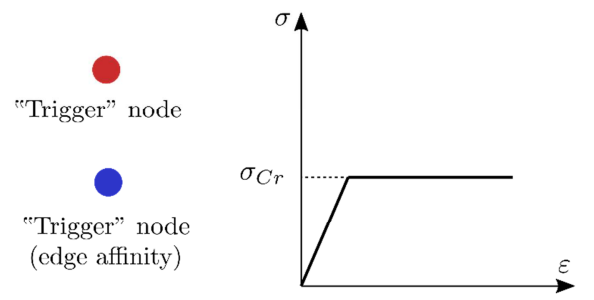

(d)

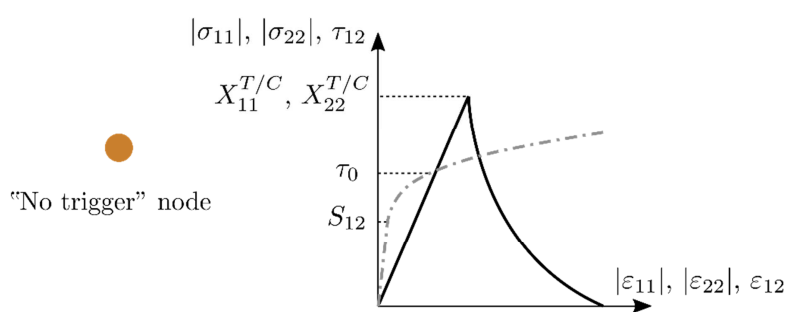

(e)

Figure 24 - Outline of the node assignment of shell elements at the crash-front using the CZone add-on.

For the SIS crush simulations, the nodes of the elements at the initial crash-front (top edge of the SIS) were assigned as "trigger" nodes, while the rest of the nodes of all shell elements were designated as "no trigger" nodes. Any shell element which contains a "trigger" node would allow the initiation of crushing, as its response (quantified by the general contact algorithm) would be limited by the imposed crush stress (Figure 24d). All nodes sharing an edge with a "trigger" node are marked as the next crushable "trigger" nodes (see Figure 24c). Elements that contain "no trigger" nodes, which are far-away from the crash-front, assume a material response following the material model described in the previous sub-section, as presented in Figure 24e. The elements are deleted by the material model definition if any of the in-plane axial damage variables are greater or equal to 0.99 , or if all the nodes of the element have completely passed through the crushing plate. For more information regarding the CZone add-on for Abaqus ${ }^{\circledR} /$ Explicit, the reader is referred to Refs $[30,42]$.

\subsection{Finite element modelling}

The geometric surface of the SIS model was constructed from the outer surface of ply 13 (refer to Figure 2), since it was the only ply surface that could be used to generate a shell mesh that connected the outer 12 plies with the inner rib of plies 13 and 14 . The $45^{\circ}$ chamfer machined in the experimentally tested SISs could not be modelled using this macro-scale approach. The crushing plate was modelled as a discrete rigid body. Figure 25a presents an isometric view of the macro-scale framework, highlighting the boundary conditions (BCs) which the model is subjected to. For simplicity, it was chosen to block the degrees of freedom, i.e. an encastre-type $\mathrm{BC}$, in the location where the SIS was experimentally fixed within the mounting base. 


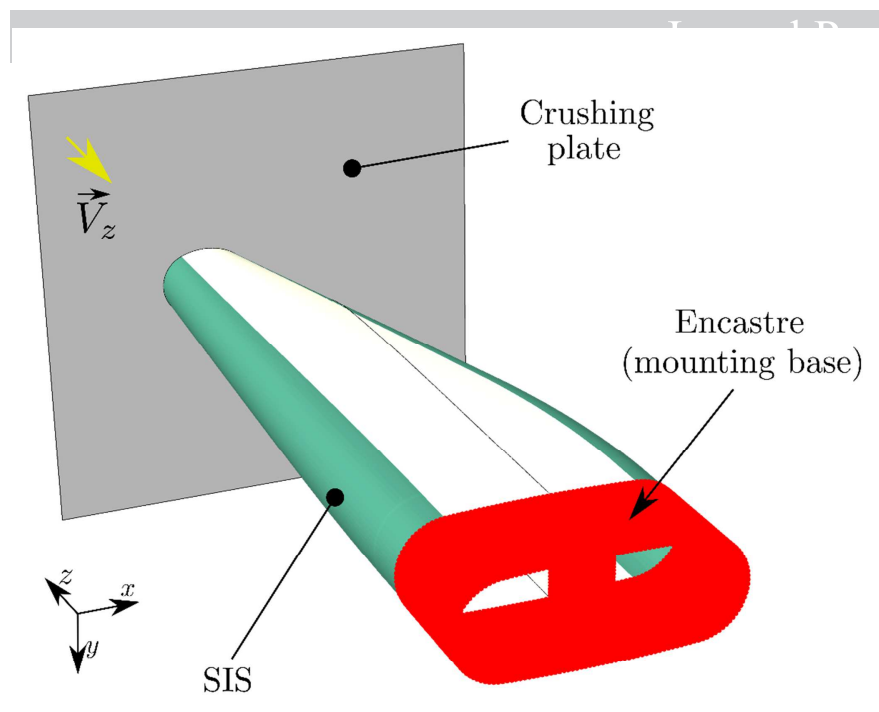

(a)

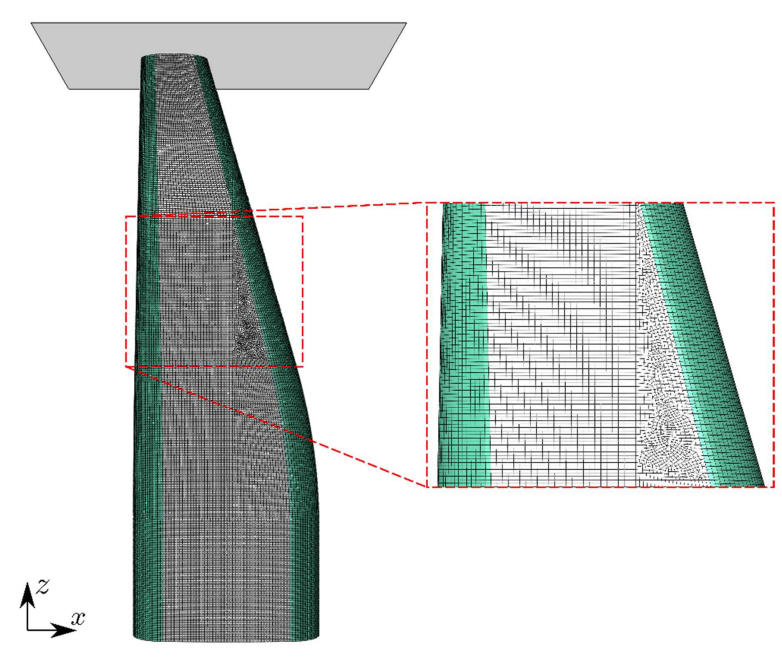

(b)

Figure 25 - (a) FE model of the SIS (composed of green and white regions to which were assigned curved and flat crush stress parameters), including the crushing plate and applied BCs (region in red); (b) shell element mesh detail of the SIS.

For the quasi-static simulation, a smooth step velocity was applied to the crushing plate, and it was assured that the kinetic energy was close to zero, guaranteeing that the simulation was indeed quasi-static. For the dynamic simulation, half the mass of the sled impactor was assigned to the crushing plate (390 $\mathrm{kg}$ ), together with the same initial velocity condition as that observed experimentally $\left(V_{z}=10.1 \mathrm{~m} / \mathrm{s}\right)$. The material properties used to simulate the structural response of the SIS are reported in Table 5, and were obtained from in-house experimental characterisation, reported in $[32,33]$.

The SIS geometry was divided into flat and curved regions to be assigned different crush stress values. This division was performed in a subjective manner based on the SIS CAD geometry that was provided. The crush stress data input for these sections were obtained from the experimental test results of the flat and tubular coupons presented in Section 2. The flat section, including the inner rib, and the curved section of the SIS, are depicted in white and green, respectively, in Figure 25. Moreover, the crush stress input data was dependent on the type of simulation, i.e. quasi-static or dynamic.

Table 6 lists these different crush stress values assigned to the two sections of the SIS, for both loading regimes. Due to the high oscillations present in the dynamic testing of the $\left[+45^{\circ} / 0^{\circ}-45^{\circ} / 90^{\circ}\right]_{\mathrm{S}}$ tubular coupons, the value assigned to the curved section of the SIS was that obtained from the $\left[0^{\circ} / 90^{\circ}\right]_{2 \mathrm{~S}}$ tubes (this slight difference in crush stress to the $\left[+45^{\circ} / 0^{\circ} /-45^{\circ} / 90^{\circ}\right]_{S}$ tubes, i.e. $\approx 2 \mathrm{MPa}$, should not have a significant effect on the quantitative predictions). It should be noted that, when running dynamic simulations, other material properties, such as elastic, strength, and fracture toughness, need to be scaled up with strain-rate [4348]. However, due to the lack of availability of strain-rate dependent data for this material, a conservative approach was taken by maintaining the quasi-static mechanical properties for the dynamic simulation. 
In-plane tensile elastic moduli

In-plane compressive elastic moduli

In-plane tensile Poisson's ratio

In-plane compressive Poisson's ratio

Shear modulus

In-plane tensile strengths

In-plane compressive strengths

Shear strength

Mode I intralaminar fracture toughness

Compressive intralaminar fracture toughness

Shear damage parameter

Maximum shear damage

Initial effective shear yield stress

Coefficient present in the hardening function

Power term present in hardening equation

$$
\begin{gathered}
E_{11}^{T}=E_{22}^{T}=63.6 \mathrm{GPa} \\
E_{11}^{C}=E_{22}^{C}=61.0 \mathrm{GPa} \\
v_{12}^{T}=0.03[-] \\
v_{12}^{C}=0.03[-] \\
G_{12}=3.69 \mathrm{GPa} \\
X_{11}^{T}=X_{22}^{T}=1046 \mathrm{MPa} \\
X_{11}^{C}=X_{22}^{C}=595 \mathrm{MPa} \\
S_{12}=100 \mathrm{MPa} \\
G_{I C}^{1 T}=G_{I c}^{2 T}=96.2 \mathrm{~kJ} / \mathrm{m}^{2} \\
G_{I c}^{1 C}=G_{I c}^{2 C}=32.5 \mathrm{~kJ} / \mathrm{m}^{2} \\
\beta_{12}=1.0[-] \\
d_{12}^{\text {max }}=0.9[-] \\
\tau_{0}=80 \mathrm{MPa} \\
C=40 \mathrm{MPa} \\
p=0.42[-]
\end{gathered}
$$

Table 5 - Ply-level material properties.

Three different composite layups were used: i) 14 plies for the flat outer section; ii) 14 plies for the curved outer section; and iii) 4 plies for the inner rib, with different material orientations associated to each ply according to the SIS layup. Due to the slight complexity in geometry arising from the varying crosssection and the junction between the inner rib and the outer envelope plies, a combination of triangular (S3R) and quadrangular (S4R) reduced integration shell elements, with hourglass control, were used to model the SIS, as shown in Figure $25 \mathrm{~b}$. The mesh was composed of approximately 59,000 elements $(\approx 500 \mathrm{~S} 3 \mathrm{R}$ elements and $\approx 58500$ S4R elements). A general contact explicit formulation, using an isotropic penalty friction approach, was used to model the contact between the crushing plate and the SIS, and for self-contact between the elements of the SIS. A value of 0.25 was used for the coefficient of friction [49,50].

\begin{tabular}{cc}
\hline Loading regime and coupon geometry & Crush stress, $\sigma_{C r}[\mathrm{MPa}]$ \\
\hline QS and flat & 118.0 \\
QS and curved & 176.2 \\
DYN and flat & 93.0 \\
DYN and curved & 138.6 \\
\hline
\end{tabular}

Table 6 - Crush stress data used for the quasi-static (QS) and dynamic (DYN) modelling of the flat and curved sections of the SIS. 


\subsection{Numerical results}

Journal Pre-proof

Both quasi-static and dynamic simulations yielded a stable progressive crushing of the macro-scale SIS model. The velocity of the sled impactor decreased as the crush progressed, in a similar manner to the experimental results, i.e. from $10.1 \mathrm{~m} / \mathrm{s}$ to approximately $5.3 \mathrm{~m} / \mathrm{s}$, as shown in Figure 26. Figure 27 shows the contour plots of the von Mises stress for different stages of the crushing process of the quasi-static SIS simulation. The stress was mostly concentrated at the zone around the crash-front, guaranteeing that the crushing process was stable, progressive, and showed no signs of buckling.

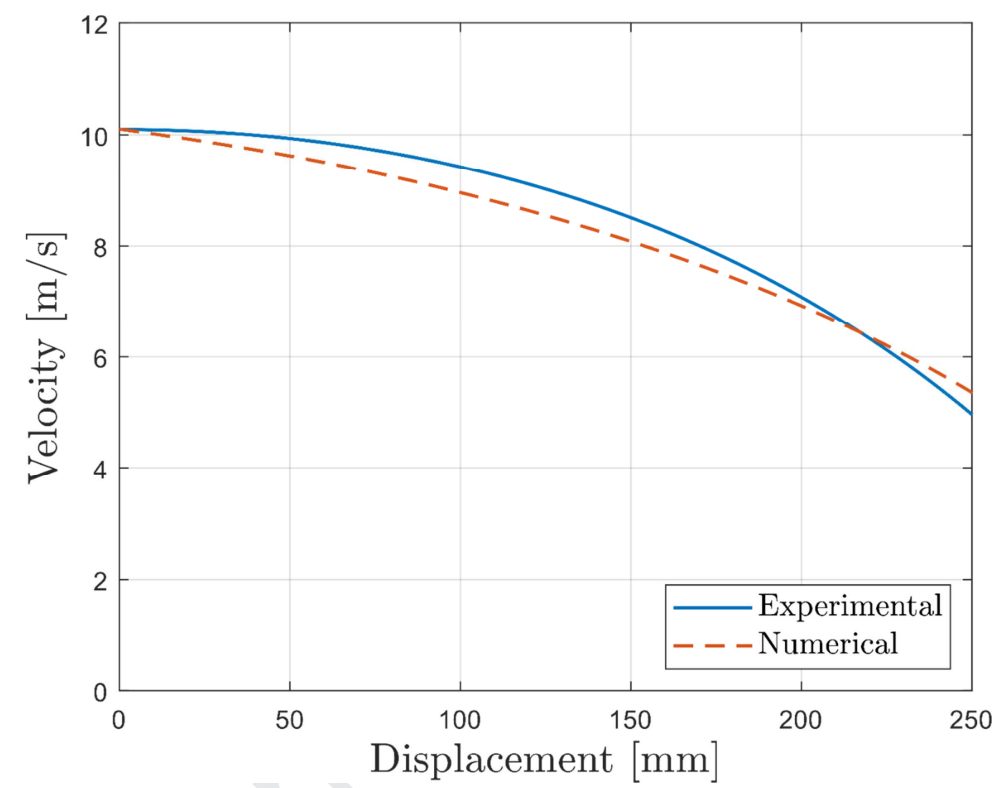

Figure 26 - Velocity-displacement profiles for the dynamic Side Impact Structure crush experiment and simulation.

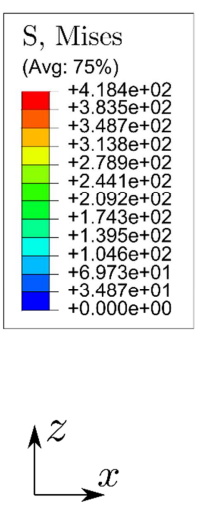

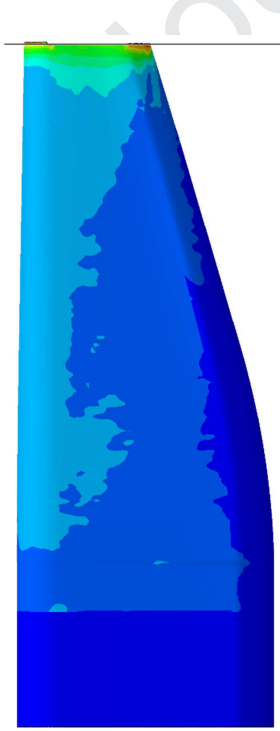

$50 \mathrm{~mm}$

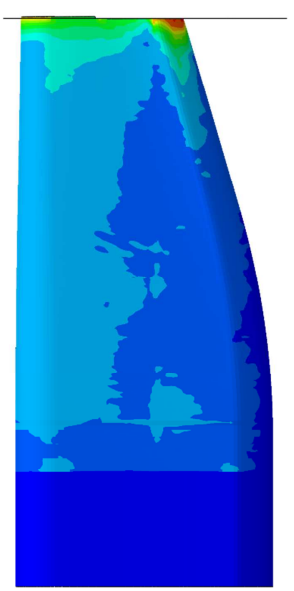

$100 \mathrm{~mm}$

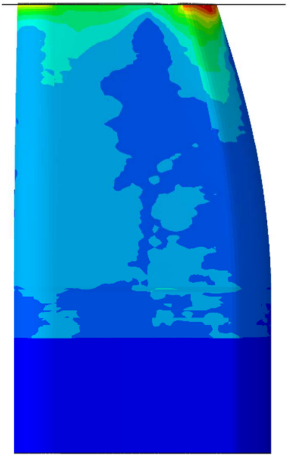

$150 \mathrm{~mm}$

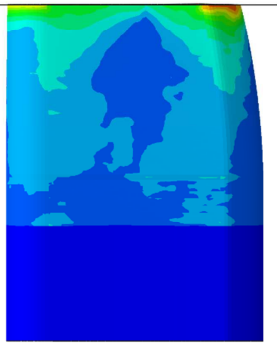

$200 \mathrm{~mm}$

Figure 27 - Numerical progression of quasi-static crushing of a Side Impact Structure, in $50 \mathrm{~mm}$ steps. 
Figure 28 shows the numerical results of the load-displacement curves of both quasi-static and dynamic simulations, overlayed on equivalent experimental results. As expected, the dynamic simulation exhibited a stiffer response, and a lower peak crush initiation load, when compared to the experimental results. A slight knee can be observed in both experimental and numerical load responses, for both loading regimes, around the $50 \mathrm{~mm}$ displacement position. At this point, the crash-front has progressed to the top region of the inner rib, which offers an additional resistance to the crush progression, resulting in this sudden change in the load response.

Analysing further the load values of Figure 28, both simulation responses were in good agreement with their respective experimental results, early on in the crush. As the crush progresses further, both numerical results tend to overestimate the experimental load responses. Since the crush stress parameters used for simulating both flat and curved regions are unaltered throughout the entire length of the SIS model, the experimental results indicate a progressive decrease in crushing efficiency for this structure, for both loading regimes. This experimental decrease can be attributed to a number of possible causes. The asymmetric ply splaying that was observed in the experimental crushing of the SIS resulted in increased lamina bending as the crush progressed. This increased lamina bending is a less efficient energy absorption mechanism than the more brittle ply fragmentation occurring when plies are not forced to bend as much, but are instead crushed axially [36]. This observed phenomenon is akin to the decrease in crushing efficiency observed in literature $[13,17,36,51]$. As the tested tube diameter to wall thickness ratio, $D / t$, increased, the crushing efficiency decreased as a result of increased lamina bending and decreased ply fragmentation. This concept also applies to the non-circular cross-section of the SIS $[17,36]$. Another possible reason for the numerical overestimation of the crushing load is due to the inefficacy of the flat coupon experiments which were used to obtain the crush stress data, used to model the flat sections of the SIS. The crushing load of the flat coupons was seen to decrease as the crush progressed, without having reached a plateau. Thus, the average crush stress measured from these tests might well be an overestimate. Other flat coupon crush tests documented in literature show the need of crushing a significant length in order to capture a stable crushing load value [5,26]. This would explain the numerical overestimation of the load responses later in the crush progression, as the flat section of the SIS increased in size.

It is worth noting that one of the two curved sections of the SIS, with an inclination which was not perpendicular to the crushing plate, could have crushed differently to the tubular coupons, hence providing a different load response. For this inclination to be more accurately modelled, a separate crush stress parameter would have had to be obtained from inclined tubular coupon tests. Such an approach would necessitate testing of various inclinations to determine the sensitivity of the crush stress parameter. This study was not performed here, and the inclined region of the SIS was assumed to behave in a similar manner to the uniaxially crushed tubular coupons. 


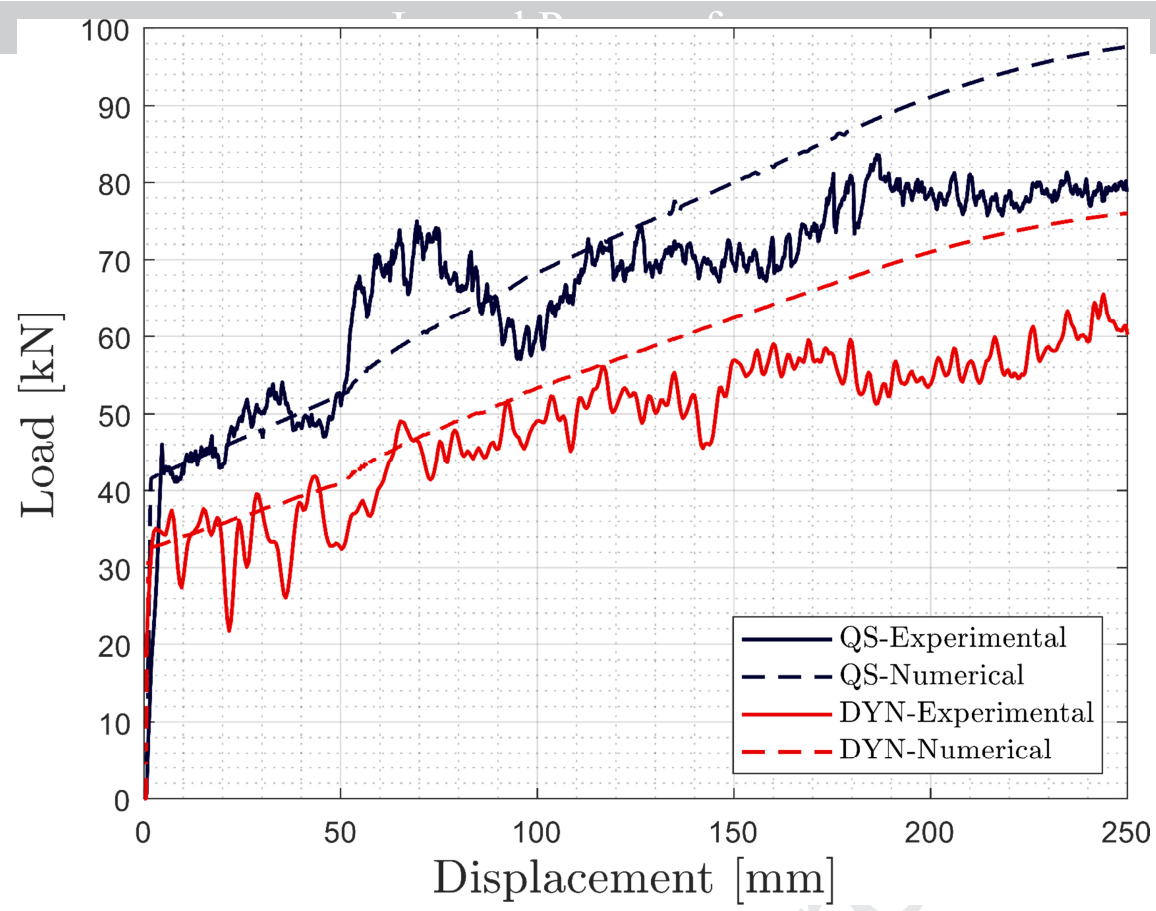

Figure 28 - Load-displacement responses of the Side Impact Structure numerical models compared to their equivalent representative experimental results, for both quasi-static (QS) and dynamic (DYN) loading regimes.

\section{Conclusions}

After comparing the experimental results obtained for the quasi-static and dynamic crushing of flat and tubular coupons for three different layups, and for the F1 Side Impact Structures, the following conclusions were drawn:

- The flat coupons crushed with symmetric ply splaying for all the tested layups and loading regimes. The average steady-state crushing stress was similar for all three layups but was consistently lower for the dynamic tests. These tests were susceptible to buckling and required some of the layups to use precrushed coupons. Although the results were quite consistent in the quasi-static regime, dynamic results show a need for further development. Thus, the flat coupon design used here, and its accompanying fixture, need to be further improved, in order to achieve longer crushing lengths with a constant unsupported length, as already suggested in literature [5,37]. This should provide more consistent crushing results for different layups and different crushing velocities.

- The tubular coupons also crushed with symmetric splaying, and the average crushing stress was similar for the $\left[0^{\circ} / 90^{\circ}\right]_{2 \mathrm{~S}}$ and $\left[+45^{\circ} / 0^{\circ} /-45^{\circ} / 90^{\circ}\right]_{\mathrm{S}}$ layups. The average dynamic crushing stress was lower for these two layups. The $\left[+45^{\circ} /-45^{\circ}\right]_{2 S}$ tubular coupons buckled under quasi-static loading but crushed progressively when tested dynamically.

- A significantly higher average crushing stress was observed for the tubular coupons over the flat ones, for both loading regimes.

- The significant load oscillations in the dynamic flat and tubular coupon results obtained from the drop weight tower highlight the need of a better understanding of both the experimental setup and the 
coupon geometries, in order to ascertain whether such oscillations are the result of the material behaviour, or a result of the setup.

- The effect of layup on coupon level crushing is not yet fully understood, partially due to the uncertainty of the conducted dynamic coupon tests. It will be essential to improve on the dynamic tests presented here in order to ascertain whether the ply layup significantly affects the crushing performance.

- The crushing efficiency of the SISs was shown to decrease as the crush progressed. Post-mortem examinations of an SIS evidenced a significant evolution of the crushing behaviour, with dominantly asymmetric outward splaying for both the flat and curved regions of the structure, possibly brought about as a result of the increasing mass of debris present at the crash-front. This crushing was evidently different to that observed in the tested coupons, which splayed symmetrically.

- The current SIS design offers a lower crush energy absorption under dynamic loading, as it is susceptible to larger jumps in the delamination fronts, which weaken the crushing capability of each ply. It is clear that by suppressing interlaminar damage, such structures could be made more efficient.

From the numerical results of the Side Impact Structure crush simulations, the authors are of the opinion that the current modelling approach being used in F1 yields decent quantitative predictions at a very reasonable computational cost. However, the progressive deviation observed in the load-displacement responses of the SISs emphasises the need to further understand the evolution of the crushing behaviour in large composite structures.

This paper has shown that this methodology for predicting crashworthiness still has some issues which need to be resolved before it can be more widely accepted by industry. The results presented here show that the first major advance needs to be on the development of the experimental coupon tests, to obtain more reliable crush stress values. The second advance would be in modelling sandwich structures, since the presented methodology has only been assessed for monolithic composites. This would be of significant importance for F1 teams attempting to predict the behaviour of their front and rear crash structures.

In conclusion, this paper has presented a comprehensive set of experimental crash test data, which when combined with the ply-level material parameters, can be used to benchmark other numerical modelling approaches for the prediction of structural composite crashworthiness.

\section{Data Availability}

Datasets related to this article can be found at http://dx.doi.org/10.17632/jd33z5d5vv.1, an open-source online data repository hosted at Mendeley Data. 
The authors gratefully acknowledge the financial support of the project ICONIC - Improving the Crashworthiness of Composite Transportation Structures. ICONIC has received funding from the European Union's Horizon 2020 research and innovation programme under the Marie Skłodowska-Curie grant agreement No 721256. The content reflects only the author's view and the Agency is not responsible for any use that may be made of the information it contains. We would also like to acknowledge the entire team at the Cranfield Impact Centre (CIC), who helped us perform the dynamic tests presented in this work.

\section{References}

[1] Savage G. Formula 1 Composites Engineering. Eng. Fail. Anal 2010;17:92-115. https://doi.org/10.1016/j.engfailanal.2009.04.014.

[2] Savage G, Bomphray I, Oxley M. Exploiting the fracture properties of carbon fibre composites to design lightweight energy absorbing structures. Eng. Fail. Anal 2004;11:677-94. https://doi.org/10.1016/j.engfailanal.2004.01.001.

[3] Lavoie JA, Morton J. A crush test fixture for investigating energy absorption of flat composite plates. Exp Tech 1994:23-6.

[4] Lavoie JA, Kellas S. Dynamic crush tests of energy-absorbing laminated composite plates. Comp. Part A 1996;27:467-75. https://doi.org/10.1016/1359-835X(95)00058-A.

[5] Feraboli P. Current efforts in standardization of composite materials testing for crashworthiness and energy absorption. 47th AIAA/ASME/ASCE/AHS/ASC Struct. Struct. Dyn. Mater. Conf., 2006. https://doi.org/10.2514/6.2006-2217.

[6] Feraboli P. Development of a modified flat-plate test specimen and fixture for composite materials crush energy absorption. J Compos Mater 2008;42:229-56. https://doi.org/10.1177/0021998307086202.

[7] Bru T, Waldenström T., Gutkin R, Robin O, Vyas G. Development of a test method for the evaluation of the crushing behaviour of unidirectional laminates. J Compos Mater 2017;51:4041-51. https://doi.org/10.1177/0021998317697811.

[8] Feraboli P. Development of a corrugated test specimen for composite materials energy absorption. J Compos Mater 2008;42:229-56. https://doi.org/10.1177/0021998307086202.

[9] Tan W, Falzon BG. Modelling the crush behaviour of thermoplastic composites. Comp. Sci. Tech 2016;134:57-71. https://doi.org/10.1016/j.compscitech.2016.07.015.

[10] Feraboli P, Wade B, Deleo F, Rassaian M. Crush energy absorption of composite channel section specimens. Comp. Part A 2009;40:1248-56. https://doi.org/10.1016/j.compositesa.2009.05.021.

[11] Deleo F, Wade B. Crashworthiness presentation. 2010.

[12] Jackson A, Dutton S, Gunnion AJ, Kelly D. Investigation into laminate design of open carbon- 
fibre/epoxy sections by quasi-static and dynamic crushing. Comp. Struct 2011;93:2646-54. https://doi.org/10.1016/j.compstruct.2011.04.032.

[13] Farley GL. Effect of specimen geometry on the energy absorption of composite materials. J Compos Mater 1986;20:390-400.

[14] Farley GL. The effects of crushing speed on the energy-absorption capability of composite tubes. J Compos Mater 1991;25:1314-29. https://doi.org/10.1177/002199839102501004.

[15] Chiu LNS, Falzon BG, Ruan D, Xu S, Thomson RS, Chen B, et al. Crush responses of composite cylinder under quasi-static and dynamic loading. Comp. Struct 2015;131:90-8. https://doi.org/10.1016/j.compstruct.2015.04.057.

[16] Liu X, Belkassem B, Jonet A, Lecompte D, Van Hemelrijck D, Pintelon R, et al. Experimental investigation of energy absorption behaviour of circular carbon/epoxy composite tubes under quasistatic and dynamic crush loading. Comp. Struct 2019;227:111266. https://doi.org/10.1016/j.compstruct.2019.111266.

[17] Farley GL. Energy-absorption capability and scalability of square cross section composite tube specimens. NASA Tech Memo 1987.

[18] Mamalis AG, Manolakos DE, Ioannidis MB, Papapostolou DP. On the response of thin-walled CFRP composite tubular components subjected to static and dynamic axial compressive loading: Experimental. Comp. Struct 2005;69:407-20. https://doi.org/10.1016/j.compstruct.2004.07.021.

[19] Liu Q, Ou Z, Mo Z, Li Q, Qu D. Experimental investigation into dynamic axial impact responses of double hat shaped CFRP tubes. Comp. Part B 2015;79:494-504. https://doi.org/10.1016/j.compositesb.2015.05.016.

[20] Palanivelu S, Van Paepegem W, Degrieck J, Van Ackeren J, Kakogiannis D, Van Hemelrijck D, et al. Experimental study on the axial crushing behaviour of pultruded composite tubes. Polym Test 2010;29:224-34. https://doi.org/10.1016/j.polymertesting.2009.11.005.

[21] Ueda M, Anzai S, Kubo T. Progressive crushing of a unidirectional CFRP plate with V-shaped trigger. Adv Compos Mater 2014;24:85-95. https://doi.org/10.1080/09243046.2014.882540.

[22] McGregor C, Vaziri R, Poursartip A, Xiao X. Axial crushing of triaxially braided composite tubes at quasi-static and dynamic rates. Comp. Struct 2016;157:197-206. https://doi.org/10.1016/j.compstruct.2016.08.035.

[23] Chambe JE, Bouvet C, Dorival O, Ferrero JF. Energy absorption capacity of composite thin-wall circular tubes under axial crushing with different trigger initiations. J Compos Mater 2019. https://doi.org/10.1177/0021998319877221.

[24] Ramakrishna S. Energy Absorption Characteristics of Knitted Fabric Reinforced Epoxy Composite Tubes. J Reinf Plast Compos 1995;14:1121-41. https://doi.org/10.1177/073168449501401007. 
[25] Kindervater C, Thomson R, Johnson A, David M, Joosten M, Mikulik Z, et al. Validation of Crashworthiness Simulation and Design Methods by Testing of a Scaled Composite Helicopter Frame Section. Proc. Am. Helicopter Soc. 67th Annu. Forum, Virginia Beach: 2011.

[26] Indermuehle K, Barnes G, Nixon S, Schrank M. Simulating composites crush and crash events using Abaqus. 50th AIAA/ASME/ASCE/AHS/ASC Struct. Struct. Dyn. Mater. Conf., Palm Springs, California: 2009.

[27] Indermuehle K, Sokolinsky V, Barnes G. Simulating Composites Crush : From the Coupon Level To Full Vehicle Crashworthiness. 52nd AIAA/ASME/ASCE/AHS/ASC Struct. Struct. Dyn. Mater. Conf., Denver, Colorado: 2011. https://doi.org/10.2514/6.2011-1735.

[28] Sokolinsky VS, Indermuehle KC, Hurtado JA. Numerical simulation of the crushing process of a corrugated composite plate. Comp. Part A 2011;42:1119-26. https://doi.org/10.1016/j.compositesa.2011.04.017.

[29] Bisagni C, Di Pietro G, Fraschini L, Terletti D. Progressive crushing of fiber-reinforced composite structural components of a Formula One racing car. Comp. Struct 2005;68:491-503. https://doi.org/10.1016/j.compstruct.2004.04.015.

[30] ABAQUS Version 2017 Documentation. Dassault Systèmes 2017.

[31] Dassault Systemes Simulia Corp. VUMAT for Fabric reinforced composites, Abaqus support document, QA Article: QA00000008519. n.d.

[32] Dalli D, Catalanotti G, Varandas LF, Falzon BG, Foster S. Mode I intralaminar fracture toughness of 2D woven carbon fibre reinforced composites: A comparison of stable and unstable crack propagation techniques. Eng. Frac. Mech 2019;214:427-48. https://doi.org/10.1016/j.engfracmech.2019.04.003.

[33] Dalli D, Catalanotti G, Varandas LF, Falzon BG, Foster S. Compressive intralaminar fracture toughness and residual strength of 2D Woven carbon fibre reinforced composites: New developments on using the size effect method. Theor Appl Fract Mech 2020. https://doi.org/https://doi.org/10.1016/j.tafmec.2020.102487.

[34] Whiting C. 2018 Formula One Technical Regulations. 2018.

[35] Collins S. https://www.racecar-engineering.com/cars/mclaren-mp4-30/ 2015.

[36] Hull D. A Unified Approach to Progressive Crushing of Fiber-Reinforced Composite Tubes. Comp. Sci. Tech 1991;40:377-421. https://doi.org/10.1016/0266-3538(91)90031-J.

[37] Barnes G. Composite crush coupon testing. Proc. 49th MIL-HDBK-17 Coord. Meet. - Crashworthiness Work. Gr., Santa Monica, CA: 2005.

[38] Reuter C, Sauerland KH, Tröster T. Experimental and numerical crushing analysis of circular CFRP tubes under axial impact loading. Comp. Struct 2017;174:33-44. https://doi.org/10.1016/j.compstruct.2017.04.052. 
[39] Johnson AF. Modelling fabric reinforced composites under impact loads. Comp. Part A 2001;32:1197206. https://doi.org/10.1016/S1359-835X(00)00186-X.

[40] Waimer M, Siemann MH, Feser T. Simulation of CFRP components subjected to dynamic crash loads. Int J Impact Eng 2017;101:115-31. https://doi.org/10.1016/j.ijimpeng.2016.11.011.

[41] Bažant ZP, Oh B. Crack band theory for fracture of concrete. Mater Struct 1983:155-77.

[42] MIT. CZone Analysis $2017 . \quad$ https://abaqusdocs.mit.edu/2017/English/SIMACAEANLRefMap/simaanl-c-czoneanalysis.htm.

[43] Hsiao HM, Daniel IM. Strain rate behavior of composite materials. Comp. Part B 1998;29:521-33. https://doi.org/10.1016/S1359-8368(98)00008-0.

[44] Gilat A, Goldberg RK, Roberts GD. Experimental study of strain-rate-dependent behavior of carbon/epoxy composite. Comp. Sci. Tech 2002;62:1469-76. https://doi.org/10.1016/S02663538(02)00100-8.

[45] Hosur M V., Alexander J, Jeelani S, Vaidya UK, Mayer A. High strain compression response of affordable woven carbon/epoxy composites. J Reinf Plast Compos 2003;22:271-96. https://doi.org/10.1177/0731684403022003844.

[46] Koerber H, Xavier J, Camanho PP, Essa YE, Martín De La Escalera F. High strain rate behaviour of 5harness-satin weave fabric carbon-epoxy composite under compression and combined compressionshear loading. Int J Solids Struct 2015;54:172-82. https://doi.org/10.1016/j.ijsolstr.2014.10.018.

[47] Kuhn P, Catalanotti G, Xavier J, Camanho PP, Koerber H. Fracture toughness and crack resistance curves for fiber compressive failure mode in polymer composites under high rate loading. Comp. Struct 2017;182:1-45. https://doi.org/10.1016/j.compstruct.2017.09.040.

[48] Kuhn P, Catalanotti G, Xavier J, Ploeckl M, Koerber H. Determination of the crack resistance curve for intralaminar fiber tensile failure mode in polymer composites under high rate loading. Comp. Struct 2018;204:276-87. https://doi.org/10.1016/j.compstruct.2018.07.039.

[49] Chiu LNS, Falzon BG, Boman R, Chen B, Yan W. Finite element modelling of composite structures under crushing load. Comp. Struct 2015;131:215-28. https://doi.org/10.1016/j.compstruct.2015.05.008.

[50] Tan W, Falzon BG, Price M, Liu H. The role of material characterisation in the crush modelling of thermoplastic composite structures. Comp. Struct 2016;153:914-27. https://doi.org/10.1016/j.compstruct.2016.07.011.

[51] Fairfull AH, Hull D. Effects of specimen dimensions on the specific energy absorption of fibre composite tubes. Sixth Int. Conf. Compos. Mater. Second Eur. Conf. Compos. Mater. ECCM)., 1987, p. $36-45$. 


\section{Declaration of interests}

$\bigotimes$ The authors declare that they have no known competing financial interests or personal relationships that could have appeared to influence the work reported in this paper.

$\square$ The authors declare the following financial interests/personal relationships which may be considered as potential competing interests: 